UC-41

Issued: October 1984

\title{
A Comparison of Two Lung Clearance Models Based on the Dissolution Rates of Oxidized Depleted Uranium
}

\author{
$L A--10214-T$
}

Kevin Craig Crist*

DE85 005190

\section{DISCLAIMER}

\begin{abstract}
This report was prepared as an account of work sponsored by an agency of the United States Government. Neither the United States Government nor any agency thereof, nor any of their employees, makes any warranty, express or implied, or assumes any legal liability or responsibility for the accuracy, completeness, or usefulness of any information, apparatus, product, or process disclosed, or represents that its use would not infringe privately owned rights. Reference herejn to any specific commercial product, process, or service by trade name, trademark, manufacturer, or otherwise does not necessarily constitute or imply its endorsement, recommendation, or favoring by the United States Government or any agency thereof. The views and opinions of authors expressed herein do not necessarily state or reflect those of the United States Government or any agency thereof.
\end{abstract}


LIST OF TABLES $\ldots \ldots \ldots \ldots \ldots \ldots \ldots \ldots \ldots \ldots \ldots \ldots \ldots \ldots \ldots \ldots \ldots \ldots \ldots$

LIST OF FIGURES $\ldots \ldots \ldots \ldots \ldots \ldots \ldots \ldots \ldots \ldots \ldots \ldots \ldots \ldots \ldots \ldots \ldots \ldots \ldots \ldots$

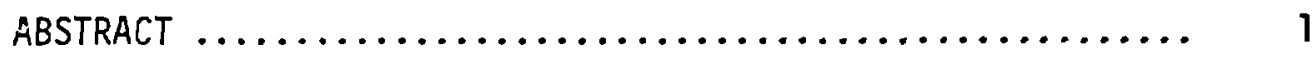

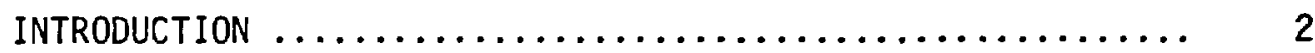

REVIEW OF. LITERATURE $\ldots \ldots \ldots \ldots \ldots \ldots \ldots \ldots \ldots \ldots \ldots \ldots \ldots \ldots \ldots \ldots \ldots$

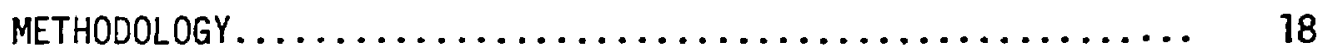

Respirable Aerosol Generation.................. 19

Dissolution Experiment ....................... 22

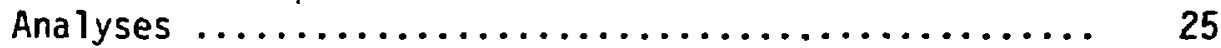

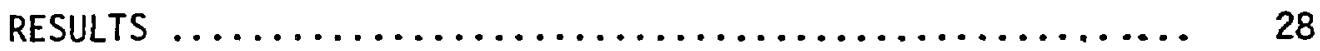

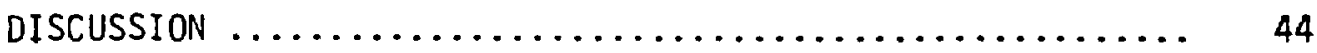

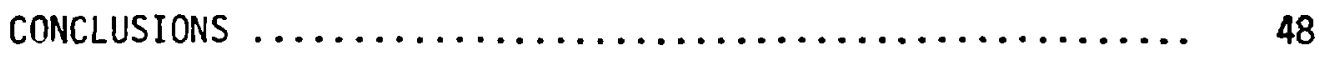

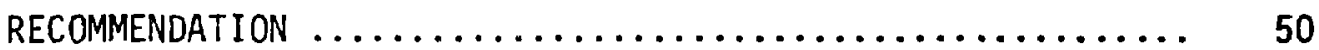

ACKNOWLEDGMENTS $\ldots \ldots \ldots \ldots \ldots \ldots \ldots \ldots \ldots \ldots \ldots \ldots \ldots \ldots \ldots \ldots \ldots \ldots \ldots$

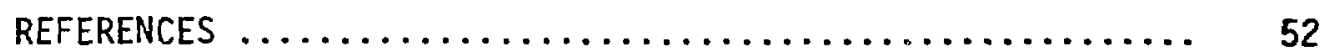

APPENDIX A

Classification Scheme of Inorganic

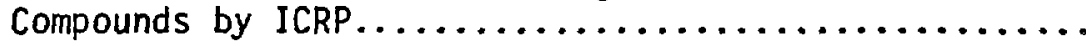

APPENDIX B

Listing of the Computer Program to Determine Dissolution Rates and Produce Plots of Mass Fraction

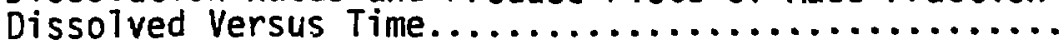




\section{LIST OF TABLES}

Table

Page

I Constants for Expontential Terms

of Equation Defining Fraction

Undissolved Equation (9)....... 16

II Penetrator oxidation Conditions ....... 18

III Components of the simulated Lung Solution ........... 24 24

IV Calculated Dissolution Rate for Each 20m1 Sample DU5 ......... 33

$\checkmark \quad$ Calculated Dissolution Rate for Each $20 \mathrm{ml}$ Sample DU9 ........ 34

VI Test of Hypothes is $\left(B_{0}=0\right)$ for Slopes

Obtained from Linear Regressions

(Figs. 8 and 9) ............ 38

VII Determination of Average Dissolution

Rate and a 97.5 Percent Confidence Interval

on That Average for DU5 and DUg ......

VIII Results from Isotopic and Gross

Gamma Analysis.......... 41

IX Predictions by the Task Group

Model and Cuddihy's Model ......... 43 


\section{LIST OF FIGURES}

Figure

Page

1 ICRP Task Group clearance model ..........

2

A simplified model for the clearance of material deposited in the respiratory tract developed by Cuddihy. . .

Dissolution of particulate mass according to Equation (9)

The relationship between und issolved mass fraction remaining ( $\left.M / M_{O}\right)$ and time.................

Penetration curve for BMRC defining respirable aerosol

Respirable aerosol generation system ......

The dissolution chamber...........

Cumulative plot of mass fraction remaining $\left(M / M_{0}\right)-$ DU5 .........

Cumulative plot of mass fraction remaining $\left(M / M_{0}\right)-$ DUg .........

Linear regression analys is on the dissolution rates calculated for samples taken after 240 hours (Table 4) - Du5 ...

11 Linear regression analysis on the

dissolution rates calculated for samples taken after 240 hours (Table 5) - Dug 
A Comparison of Two Lung Clearance Models Based on the Dissolution Rates of Oxidized Depleted Uranium

by

Kevin Craig Crist

ABSTRACT

An in-vitro dissolution study was conducted on two respirable oxidized depleted uranium samples. The dissolution rates generated from this study were then utilized in the International Commission on Radiological Protection Task Group lung clearance model and a lung clearance model proposed by Cuddihy. Predictions from both models based on the dissolution rates of the amount of oxidized depleted uranium that would be cleared to blood from the pulmonary region following an inhalation exposure were compared. It was found that the predictions made by both modeis differed considerably. The difference between the predictions was attributed to the differences in the way each model perceives the clearance from the pulmonary region. 
INTRODUCTION

Research has been performed at Los Alamos National Laboratory to determine the dissolution behavior of oxidized depleted uranium (DU) in lung fluid simulant in a effort to gather data which could be used to determine the pulmonary to blood transfer rate of inhaled oxidized DU. This information was taken one step further by utilizing the data in two biomathematical clearance models to predict the clearance characteristics of that material. From these models a quantitative description of how the material will be cleared from the pulmonary region was estimated. The two models utilized were the International Commission on Radiological Protection (ICRP) Task Group mode ${ }^{(1)}$ and a clearance model developed by cuddihy.

The major complication involved with this type of experiment is that the environment in which the the study is carried out, must closely resemble the ervironment found in the lung. The environment of the pulmonary region was simulated in the experiment to obtain an estimate of the dissolution behavior. For example, the solvent used in the dissoiution study had to chemically resemble the lung fluid found in the pulmonary region; and other physiological conditions such as temperature and $\mathrm{pH}$ had to be duplicated. All of these components can affect the American Industrial Hygiene Association Journal. 
dissolution behavior of a material. There were also complications with the interpretation of the data generated from the experiment. The data was analyzed based on theoretical approximations developed by Mercer. (3) However, the data did not totally conform with theory. Consequently, some major assumptions were made about the data in order to use the theoretical approximations.

Quantitative descriptions of the removal processes from the respiratory system are important because they provide dose effect estimates from an inhalation exposure. Thus, the data generated from this study can be used as an integral part in determining the possible biological effect from an inhalation exposure to oxidized depleted uranium (DU) aerosol.

The objective of this thesis was three fold: (1) to determine the dissolution rates for two respirable ou samples, (2) to determine the specific pulmonary clearance characteristics of oxidized DU, (3) to compare two lung clearance models, by determining the predicted values for pulmonary clearance from such models for the two dissolution rate constants with the widest numerical range. 


\section{REVIEW OF LITERATURE}

Dissolution studies have been performed to gain information on the human risk associated with the inhalation of uranium oxide particles produced when firing anti-tank shells called penetrators. The penetrators are formed from uranium metal rods produced from a raw stock of uranium tetrafluoride $\left(U F_{4}\right)$. Elder and Tinkle $e^{(4)}$ concluded that when the penetrators were subject to fire (temperatures exceeding $500^{\circ} \mathrm{C}$ ) respirable oxidized oU aerosols of $\mathrm{UO}_{2}$ and $\mathrm{U}_{3} \mathrm{O}_{8}$ were produced. If these aerosols are readily transported into the blood stream the hazard associated with inhalation will be one of chemical toxicity, with the critical organ being the kidney. (5)

When assessing the harmful effects from inhalation of a chemical toxin, lung clearance plays an essential role in determining the harmful reaction. Consequently, in order to determine the dose to the body organs from inhalation of DU the lung clearance mechanism and rates must be determined. (6)

The total clearance of material deposited in the pulmonary region is assumed to be accomplished by three pathways $(1,7,8,9)$; lung to gastrointestinal tract (GI), lung to lymph, and lung to blood. Clearance of particles to the GI tract involves transport via the moving blanket of mucous, which covers the respiratory airways, up to the throat where the particles are swallowed or expectorated. $(6,7)$ These particles may be free or contained in 
phagocytes. This may involve direct transport of particles, transport of phagocytes (engulfed particles), and a combination of the two. However, the principle mechanism for this type of clearance may vary depending on deposition site and particle composition. In the lung to lymph pathway, a portion of the deposited material also undergoes phagocytosis. (7) The responding phagocytes are transported to the lymph system. $(7,10)$ Finally, in the lung to blood pathway, the material is first dissolved in the interstitial fluid, with subsequent transfer to the blood stream. $(2.7)$ Dissolution controls the rate of transfer, from lung to blood, because it is the slowest step in the transfer of material from lung to blood. $(2,7,11)$

The lung to GI and lung to lymph pathways are both mechanical processes and have been found to be relatively independent of the chemical and physical form for relatively insoluble materials. $(10,12,13)$ These mechanical processes play a major role in clearance of material deposited in the respiratory tract during the initial phases of lung clearance. (1) However, for long term clearance of relatively insoluble material deposited in the pulmonary region, dissolution which is a function of the physiochemical nature of the compound, $(3,9,14)$ plays the major role in the clearance of material. (3) consequently, when dealing with insoluble material, deposited in the pulmonary region, dissolution of that material controls the long term systemic contamination from an inhalation exposure. 
A relatively simple method of assessing particle solubility, when biological data is limited, is by in-vitro dissolution studies. When conducting in-vitro dissolution studies, the composition, temperature, and $\mathrm{pH}$ of the lung simulant used must be matched to those of the lung to insure that dissolution rates observed in-vitro and in-vivo are comparable. $(9,13,14,15,16,17)$ Simulants of lung interstitial fluid (formerly called Gamble's solution) are based on extrapolation of molar equivalent concentrations from a bar graph based on ionic concentration information available on the composition of lung interstitial fluid. (18) The solution represents an environment equivalent to the deep pulmonary region of the lung.

Since a study of all possible aerosol forms that could be involved in human inhalation exposure is impractical, methods were developed to analyze experimental data, (i.e. in-vitro dissolution studies) which can be used to extrapolate such data to man. (13) One particular method is the use of biomathematical models for inhalation exposure. $(1,2,13,19)$

Currently, the most widely used model for describing retention and dosimetry of inhaled radionuclides was developed by the ICRP Task Group on Lung Dynamics for Committee II on the Internationa? Radiological Protection Commission (ICRP). (1) The ICRP Task Group defined the respiratory tract in terms of three major compartments; nasopharynx $(N-P)$, trachea and the bronchial tree $(T-B)$, and pulmonary $(P)$. An illustration of this model is given 
in Figure 1. Clearance from these compartments is described in terms of 10 different absorption and translocation processes. For each clearance pathway, two values are assigned, the biological half time for that pathway, and the regional fraction cleared by that pathway. ${ }^{(20)}$ The ICRP Task Group grouped nine major classes of inorganic compounds into three categories. A listing of these classes is presented in Appendix A. Each of these categories is expected to produce a range of clearance characteristics. From these clearance characteristics, the two values for each clearance pathway is assigned.

According to Cuddihy, ${ }^{(2)}$ the ICRP model is not adequate, especially in the solubility classification scheme used for projecting clearance fractions. The ICRP model determined the clearance rates by the chemical form of the compound. The major oversight with this is that solubility can vary greatly within a particular chemical form. For example, Newton ${ }^{(21)}$ found from dissolution studies conducted on heat treated plutonium oxide particles, that dissolution rate constants varied by more than a factor of 10. Newton did not discuss the causes of this variability, however, solubility is a function of the physical and chemical properties of the particular compound. $(13,15)$ Mercer ${ }^{(3)}$ proposed that the role of dissolution is directly proportional to the total surface area of the particle. To determine solubility constants experimentally and to use this calculation to estimate lung clearance of deposited material, 
requires measurements of particle surface area. (2) Consequently, the ICRP greatly oversimplifies the role of

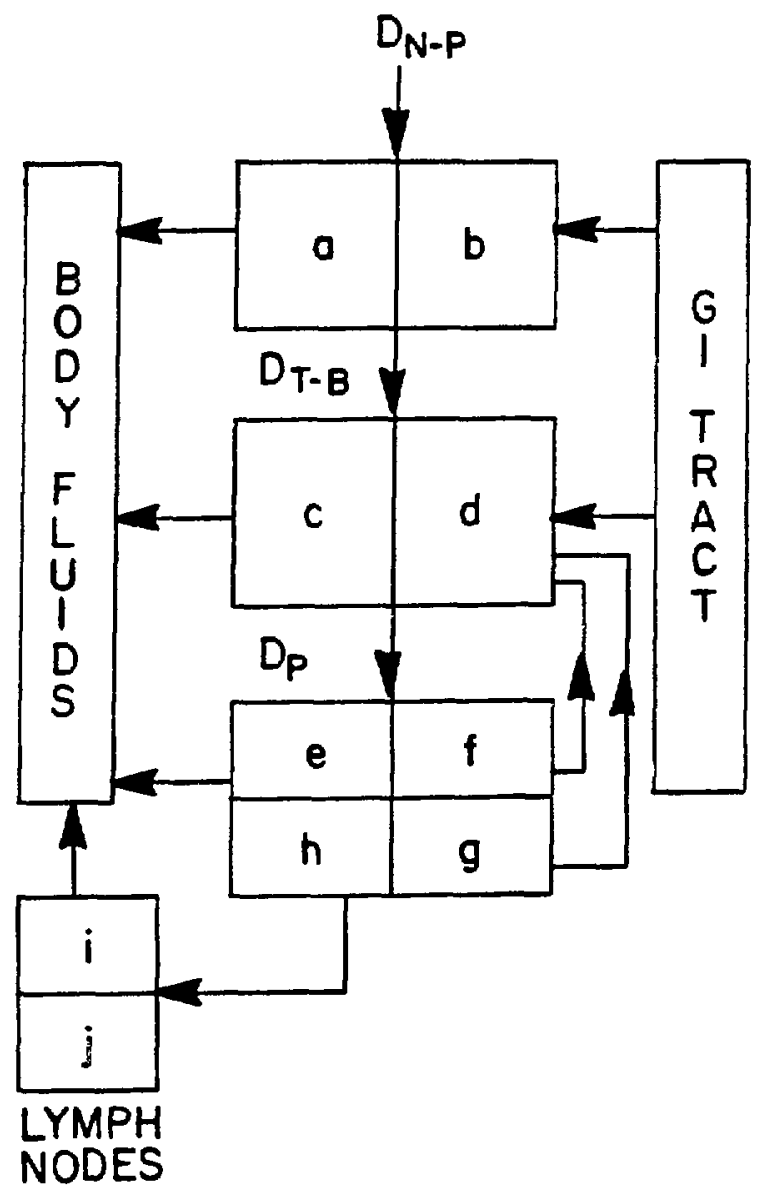

Figure 1--ICRP Task Group clearance mode1.(1) The diagram depicts three respiratory compartments: nasal passages. NP; tracheobronchial airway. TB; and pulmonary region, $P$, and their clearance pathways, $a-h$.

solubility in lung clearance which, in turn, restricts the model from predicting lung clearance of a specific compound. 
Recently, a biomathematical lung clearance model was introduced at the Snowbird Actinide Workshop. (2) The model is designed to utilize derived dissolution rates for specific compounds. These absorption rate functions are coupled with mechanical clearance rate functions to project overall rates of clearance for the material from all regions of the respiratory tract. Figure 2 illustrates a simplified version of Cuddihy's model.

For the pulmonary region, clearance is assumed to be accomplished by three pathways: lung to GI, lung to lymph, and lung to blood. The model states that the clearance of particles by the former two pathways are controlled by mechanical clearance rate functions, while the latter is governed by an absorption rate function. The absorption rate function, which is obtained from in-vitro dissolution studies, can be combined mathematically with previously derived mechanical clearance rate functions to estimate the fractions of material deposited in the pulmonary region cleared by eacin of the three pathways.

The fractions of material cleared by each pathway can be predicted from this model if the clearance rate constants for each pathway are known. The mathematical interpretation of the above is as follows:

If it is assumed that the total clearance from the pulmonary region is accomplished by three pathways, then the amount of material cleared from the pulmonary region in an instantaneous 
time interval can be expressed as a function of the clearance rates for those pathways:

$$
\frac{d L}{d t}=-\left(K_{1}+K_{2}+K_{3}\right) L
$$

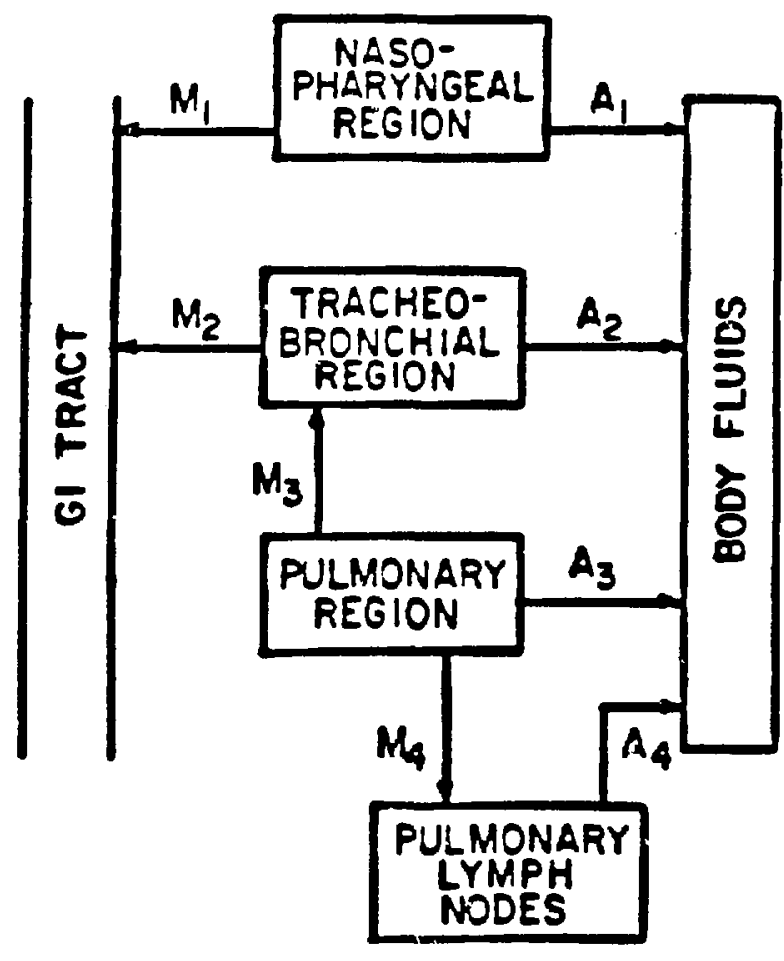

$M_{i}=$ MECHANICAL CLEARANCE FUNETIONS $A_{i}=$ ABSORPTION RATE FUNCTIONS

Figure 2--A simplified model for the clearance of material deposited in the respiratory tract developed by Cuddihy. (2) 
where:

$$
\begin{aligned}
K_{1}= & \text { clearance rate for particles transported to } G I \\
K_{2}= & \text { clearance rate for particles transported to lymph } \\
K_{3}= & \text { dissolution rate for particulate material transported } \\
& \text { to blood } \\
L & =\text { mass of material in the pulmonary region. }
\end{aligned}
$$

Intergration of Equation (1) yields:

$$
L(t)=e^{-\left(K_{1}+K_{2}+K_{3}\right) t+c}
$$

By applying an initial condition that $L(t)=L_{0}$ at $t=0$, where $L_{0}$ is the initial load on the pulmonary region, Equation (2) can be expressed as:

$$
L(t)=L_{0} e^{-\left(K_{1}+K_{2}+K_{3}\right) t}
$$

In order to express the fraction cleared by a pathway in terms of the three clearance rates, the mass of material cleared over time by that pathway must be determined. For example, the mass of material transported to blood in an instantaneous time interval can be expressed as follows:

$$
\frac{d B}{d t}=K_{3} L
$$

where: $B$ is the mass of material which has been transported to blood. 
Equation (4) can be substituted into Equation (3) to express dB in terms of the three rate constants:

$$
\frac{d B}{d t}=K_{3} L_{0} e^{-\left(K_{1}+K_{2}+K_{3}\right) t}
$$

Integration of Equation (5) between 0 and $t$ yields the following solut

$$
B(t)=B_{0}+\frac{K_{3} L_{0}}{K_{1}+K_{2}+K_{3}} \quad\left(1-e^{-\left(K_{1}+K_{2}+K_{3}\right) t}\right.
$$

where: $B_{0}$ is the concentration of the material in the blood at $t=0$.

By assuming that the concentration of the material in the blood is zero prior to the exposure $\left(B_{0}=0\right.$ at $\left.t=0\right)$, and by letting $t$ go to infinity the total amount of material cleared to blood (B) can be expressed as follows:

$$
B=\frac{K_{3} L_{0}}{\left(K_{1}+k_{2}+K_{3}\right)}
$$

From Equation (7) the fraction eventually cleared to blood from the pulmonary region $\left(B / L_{0}\right)$ can be expressed in terms of the clearance rates for the three pathways:

$$
\frac{B}{L_{0}}=\frac{K_{3}}{\left(K_{1}+K_{2}+K_{3}\right)}
$$

As can be seen from Equation (8), once the rate constants are known, determining the fractions is relatively simple. As 
previously mentioned, the mechanical lung clearance processes have been found to be relatively independent of the physical and chemical form for relatively insoluble material. Consequentiy, the mechanical clearance rates determined from previous studies $(10,20)$ on similar compounds should be applicable to this experiment.

The mechanical clearance rate constants for insoluble particles transported between the pulmonary compartment and lymph nodes was reported by Thomas $(10)$ to be $0.0001 / d a y$. The clearance rate constant for particles transported between the pulmonary and the GI tract can be obtained from the ICRP publication, ${ }^{(20)}$ which reported that for insoluble material (Class $Y$ ) transportation between the pulmonary and GI tract will have a clearance rate of $0.0014 /$ day. Oxidized DU is expected to satisfy the criteria for a Class.Y compound (refer to Appendix A.).

The third clearance rate, governing lung to blood transfer, will be estimated by the in-vitro dissolution study detailed in this thesis. In order to make the correlation that the clearance rate generated from the in-vitro dissolution study will be similar to an in-vivo clearance rate it must be assumed that the specific surface areas found in both are similar. This is crucial, because the clearance rate is a function of the specific surface area. $(3,15)$ Studies conducted by Eidson ${ }^{(22)}$ have shown the above assumption to be fairly accurate. Eidson reported close agreement (within a factor of two) between the in-vitro and in-vivo clearance rates. 
A dissolution rate (which is assumed to be the clearance rate) for transfer from the pulmonary to blood can be obtained from a dissolution study by plotting the fraction on semi-log paper of ou remaining undissolved $\left(M / M_{0}\right)$ versus time, where $M$ equals the mass remaining at time $t$, and $M_{0}$ is equal to the initial mass ( $M$ at $t=0)$. The fraction of $D U$ remaining $\left(M / M_{0}\right)$ is a function of two parameters, $\beta$ and $\sigma$, where $\beta$ is equal to the product of time $(t)$, dissolution rate constant $(K)$, and the ratio of the surface area to particle mass $\left(S_{p}\right) ; \sigma$ is the anti-log of the geometric standard deviation of the aerosol size distribution. This relationship is graphically illustrated in Figure $3 .{ }^{(3)}$

The dependency of $M / M_{0}$ on $B$ is relatively straight forward. The smaller the specific surface area becomes (the larger the particle size), the slower the dissolution rate will be. The relationship between $M / M_{0}$ and $\sigma$ also hinges on the specific surface area, but as can be seen from Figure 3, this dependency only takes place when less then $30 \%$ of the material remains undissolved. For the experiment reported in this thesis, approximately $80 \%$ of the sample remained undissolved; consequently, the $\sigma$ of the sample will have little effect on the dissolution rate and the results measured will relate to the short term component of the total solubility.

The semi-log plots of $M / M_{0}$ verses time in this experiment will be similar to the plot shown in Figure $4 .^{(3)}$ Mercer proposed that this plot could be approximated by the sum of two exponentials (the two straight line extrapolations in Figure 4). 


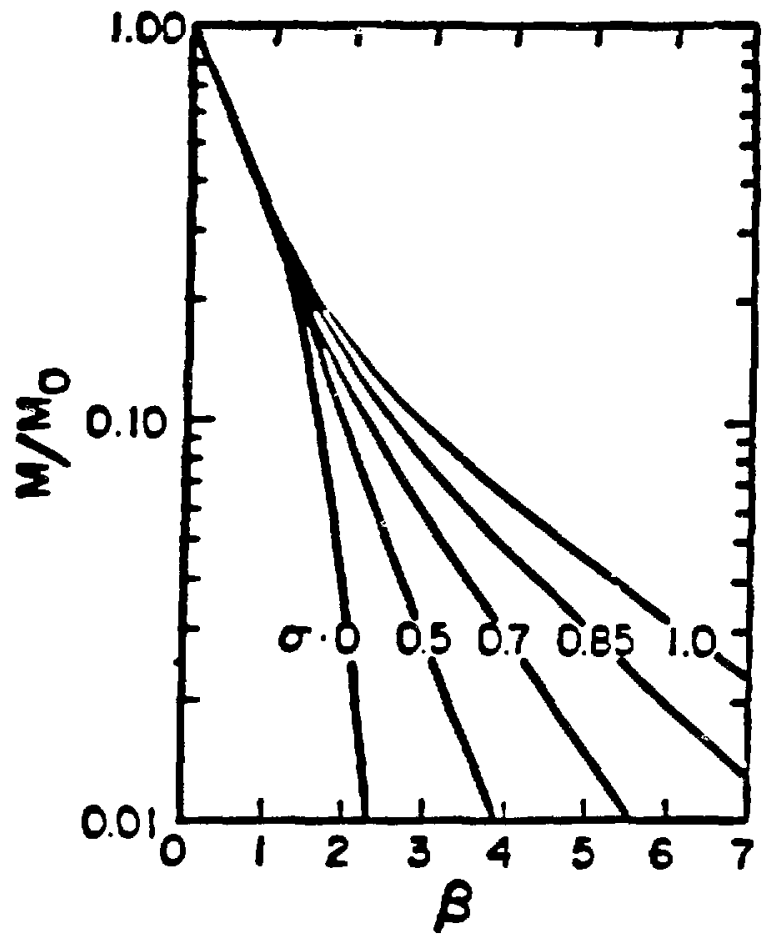
Figure 3--Dissolution of particulate mass according to Equation
(9).(3)

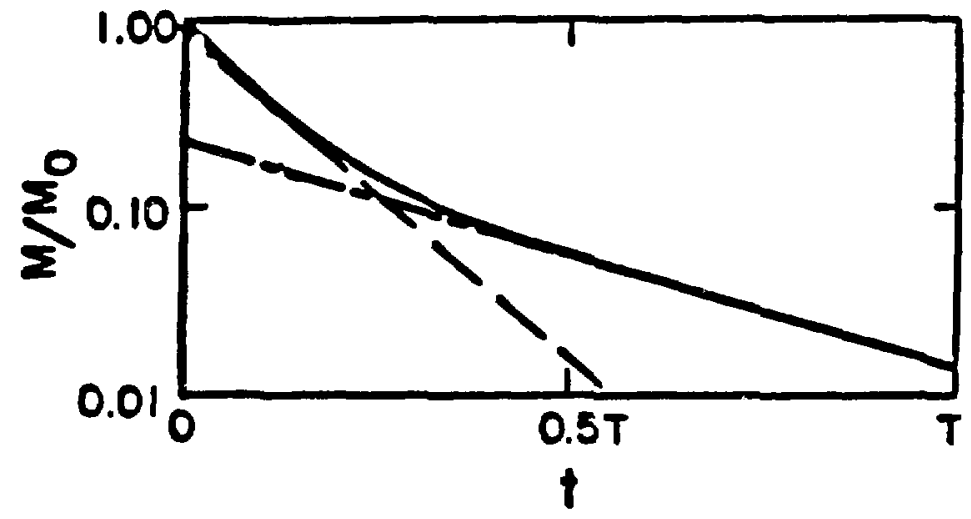

Figure 4--The relationship between undissolved mass fraction remaining $\left(M / M_{0}\right)$ and time. (15) 
The solution to this approximation is:

$$
M / M_{0}=f_{1} e^{-\lambda_{1} \beta}+f_{2} e^{-\lambda_{2} \beta}
$$

where: $f$ and $\lambda$ are sole functions of the $\sigma$.

Mercer solved for $f$ and $\lambda$ for various $\sigma$. These constants are given in Table I. From this approximation (Equation (9)) the estimated clearance rate for pulmonary to blood transfer of DU can be determined.

TABLE I

Constants For Exponential Terms of Equation Defining Fraction Undissolved Equation $(9)(9)$

\begin{tabular}{llcll}
\hline$\sigma$ & $f_{1}$ & $f_{2}$ & $\lambda_{1}$ & $\lambda_{2}$ \\
\hline 0.5 & 1.0 & 0 & 1.18 & - \\
0.7 & 0.62 & 0.38 & 1.76 & 0.65 \\
0.85 & 0.75 & 0.25 & 1.533 & 0.425 \\
1.0 & 0.77 & 0.23 & 1.536 & 0.33
\end{tabular}

The second exponential in Equation (9) only has impact on the last $20 \%$ of the material remaining. Consequently, the first exponential is sufficient in approximating the dissolution for $80 \%$ of the material and results in only minimal error in the last $20 \%$. Equation (9) can then be reduced to the following using the previously noted definition for $B$ (pg.11):

$$
M / M_{0}=f_{1} e^{-\lambda_{1} \beta}=f_{1} e^{-\lambda_{1} S_{p} K t}
$$


Equation $(10)$ can be redefined as follows:

$$
\lambda^{\prime}=\lambda_{1} S_{p} K=K_{3}
$$

where: $\lambda^{\prime}$ is the dissolution rate for the material in units of days $^{-1}$ and is assumed to be the clearance rate for iung to blood transfer $\left(K_{3}\right)$.

From Equation (11) the dissolution rate for oU can be determined if the specific surface area $\left(S_{p}\right)$ of the sample is known; the dissolution rate constant $k$ is obtained from Equation (10) by determining the value for $M / M_{0}$ at time $(t)$ from the semi-log plot (Figure 4); and $\lambda_{1}$ can be obtained from Table I. (3) However, since $\sigma$ has little bearing on the dissolution rate, for $M / M_{0}>0.3$ a $\sigma$ of 0.5 can be used. The dissolution rate $\left(\lambda^{\prime}\right)$ can also be determined by simply taking the slope of an exponential fitted to a plot of mass fraction remaining $\left(M / M_{0}\right)$ versus time (Figure 4). From Equation (11) it can be seen that the redefined $\lambda^{\prime}$ is simply the slope of that exponential.

In summary, the dissolution rate needed for Cuddihy's model can be determined by one of two ways. (1) By plotting the mass fraction dissolved vs. time on semi-log paper and then approximating this line by a straight line, with the slope of the straight line being the dissolution rate, or (2) by solving for $\lambda^{\prime}$ in Equation (11). This will require determining the specific surface area of the sample. 


\section{METHODOLOGY}

The dissolution characteristics of oxidized DU were investigated. This involved determining the dissolution rate of oxidized DU over time in lung fluid simulant.

The oxidized DU was obtained from studies conducted by Elder. (4) Elder subjected penetrators (see Literature Review) to air and air- $\mathrm{CO}_{2}$ mixtures at varying temperatures and flow rates. The oxidized residue from Elder's study was used in this experiment. Table II lists the conditions under which the oxidized material was produced. The two samples with the widest numerical range in dissolution rate constants were chosen for this thesis. The two samples from Elder's study used in this thesis were DU5, and DUg (Table II). Scripsick ${ }^{(23)}$ has shown these two samples to have the greatest variation in the long term dissolution rates.

TABLE II

Penetrator Oxidation Conditions (4)

Sample No.

DU5

DU6

DU7

DU8

DU9
Atmosphere

Air

Air

Air

$\mathrm{CO}_{2}$-Air Mixture

Air
Nominal Temp.

$\left({ }^{\circ} \mathrm{C}\right)$

600

700

900

500

700 
From each of the samples obtained from Elder ${ }^{(4)}$ a set of eight respirable samples were collected according to the British Medical Research Council (BMRC) criteria. (24) A respirable sample from each set was placed in a dissolution chamber in which lung fluid simulant was passed through. The effluent from this chamber was then analyzed for DU concentration by a delayed neutron technique. ${ }^{(25)}$ The respirable samples were also analyzed for isotopic composition and total uranium concentration prior to the dissolution study.

RESPIRABLE AEROSOL GENERATION:

Respirable oxidized DU samples were collected according to the BMRC criteria for DU5 and DU9. (24) The BMRC criteria is illustrated in Figure 5 . The respirable samples were collected by passing suspended oxidized DU through a horizontal elutriator operated under the conditions specified to match the BMRC criteria. (24) The set up for the aerosol generation is illustrated in Figure 6 .

The elutriator must be operated at atmospheric pressure to insure proper performance. ${ }^{(24)}$ This was accomplished by placing a tee, which was open to the atmosphere, upstream from the elutriator. The air flowing through the tee was filtered by an in-line high efficiency particulate air (HEPA) filter to prevent contamination from the ambient air. 


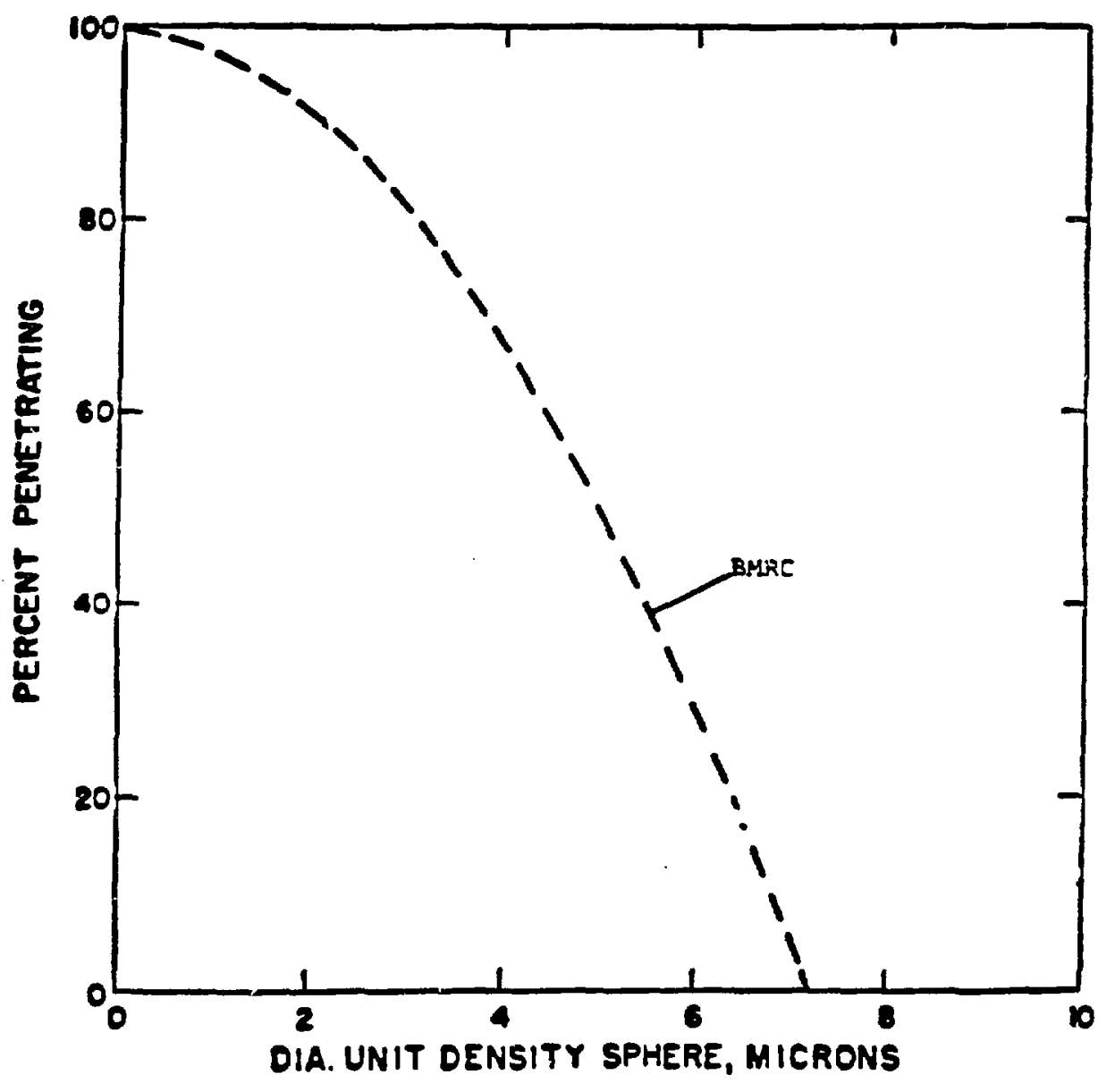

Figure 5--Penetration curve for BMRC defining respirable aerosol. 


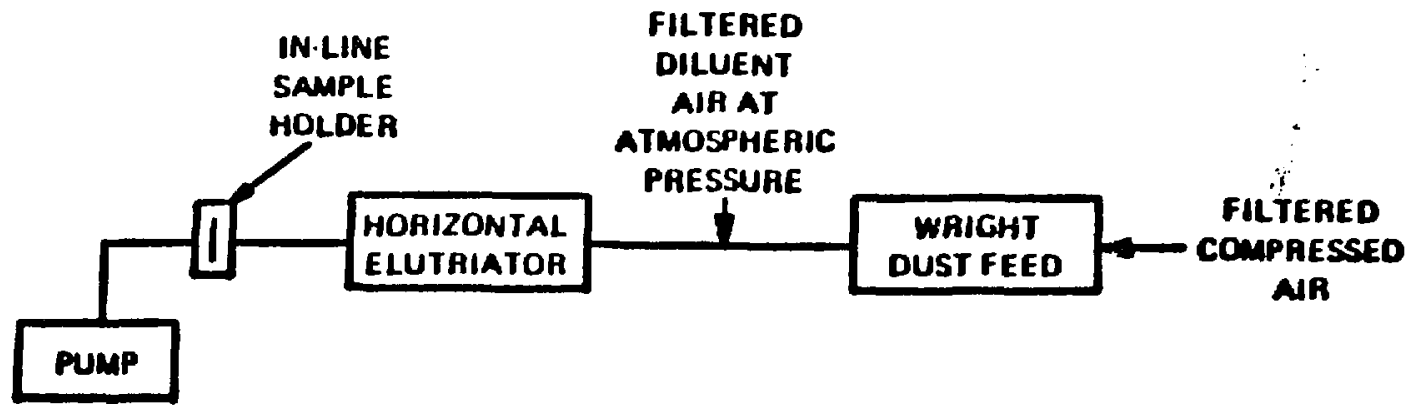

Figure 6--Respirable aerosol generation system.

Suspended oxidized DU was supplied to the horizontal elutriator by means of a Wright Dust Feed. ${ }^{(26)}$ Positive pressure was placed on the upstream side of the dust feed using compressed filtered air to mairtain a sufficient flow of air through the dust feed. However, the positive pressure was kept low enough to maintain a slight negative pressure on the down stream side of the elutriator, thus, allowing a slow influx of air at the tee. Four samples in parallel were collected down stream from the elutriator on 5 um pore size, $25 \mathrm{~mm}$ diameter millipore filters. This size filter was used to minimize the pressure drop across the filter and because the filter has been shown to be $98-99 \%$ efficient for respirable material. (27)

The volume of air flowing through the system was monitored with a pressure transducer attached across the elutriator. This transducer was calibrated against a dry test meter, which was placed upstream from the elutriator prior to each run. 


\section{DISSOLUTION EXPERIMENT:}

The dissolution chamber that was used in this experiment was patterned after a design by Moss and Kanapilly. (15) The dissolution chamber. a flowpast system, is shown in figure 7. The oxidized ou sample for DU5 and Dug. which were collected on a $5 \mu \mathrm{m}$ Millipore filter, were sandwiched between two Nuclepore filters $(0.1 \mu \mathrm{m}$ pore size).

Polyethyelene support screens were added to the front side of the sandwich. In contrast, the back side of the sandwich was sealed off with silicon rubber, since solvent only entered and left from one side of the sandwich.

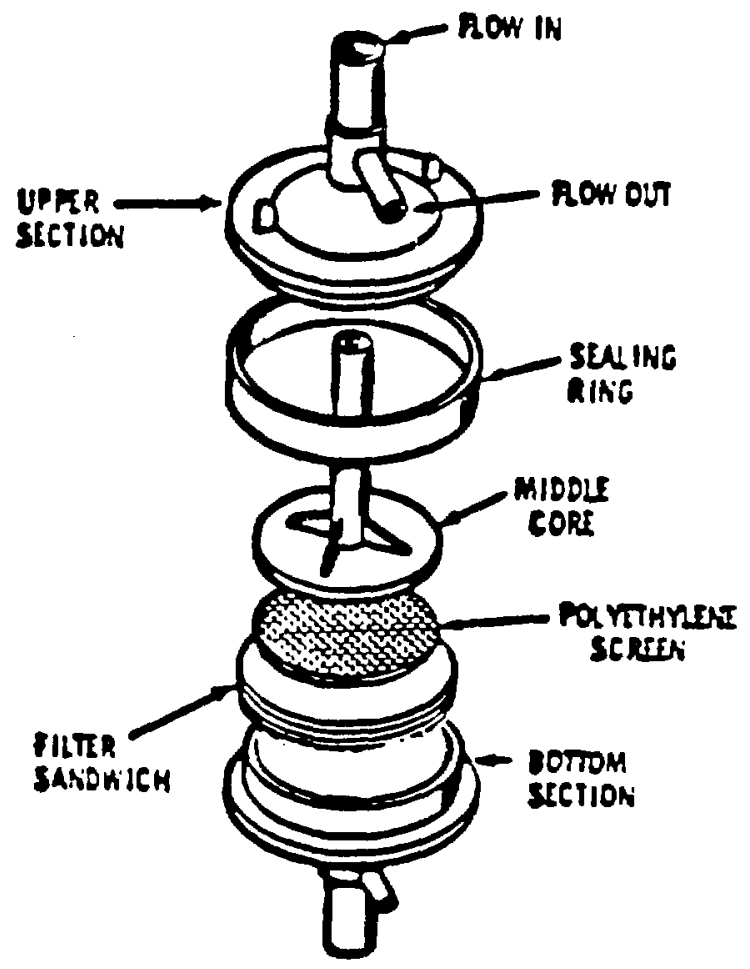

Figure 7--The dissolution chamber. 
The solvent (lung fluid simulant) entered into the center of the dissolution chamber, then flowed radially outward over the front of the filter sandwich, thereby allowing the ou to diffuse through the Nuclepore filter. (28) The lung fluid simulant was not recirculated through the chamber, but rather this was an open ended system. The above was carried out in order to simulate, as close as possible, the conditions found in the pulmonary region.

The lung fluid simulant was delivered to the dissolution chamber by a peristaltic pump, at a constant flow rate of one $\mathrm{mL}$ per minute. According to Moss, ${ }^{(15)}$ if the rate of flow through the dissolution chamber is kept above $0.7 \mathrm{ml} /$ minute then the dissolution rate will be independent of the flow rate. Consequently, a $1 \mathrm{ml} /$ minute flow rate was chosen because it allowed for a margin of error in the flow rate without affecting the dissolution and it was a convenient rate with which to work. The $\mathrm{pH}$ of the simulant was maintained at 7.4 by slowly bubbling 95 per cent $\mathrm{O}_{2}$ and 5 per cent $\mathrm{CO}_{2}$ through the simulant, as suggested by Moss. (18) The temperature of the solution was also maintained by coiling the tubing transporting the simulant to the dissolution chamber in a constant temperature bath at $37^{\circ} \mathrm{C} \pm 0.5^{\circ} \mathrm{C}$.

The electrolytic composition of the lung fluid simulant was based on information presented in a paper written by Moss. (18) The components of the solution are shown in Table III. The solution was designed to model the lung interstitial fluid. A comparison completed by Kalkwarf, (29) showed that the simulant and the interstital fluid are almost identical. The protein components in actual lung fluid were 
represented by equivaient amounts of citrate as suggested by Moss. (18) The lung fluid simulant was prepared in 156 liter batches, using deionized water. To increase the rate of solution, 95 per cent of the final volume of water was preheated to $37^{\circ} \mathrm{C}$. The salts were mechanical premixed in six liter flasks, to aid in dissolving the salts. The salts were then transferred to the preheated water in the same order as liste in Table III. During this procedure the $\mathrm{pH}$ of the solution would drift basic (pH 8-9) causing a precipitate. This was controlled by lowering the $\mathrm{pH}$ to approximately 7 with dilute $\mathrm{HCL}$.

\section{TABLE III}

Components of the Simulated Lung Solution

\section{Component}
(a) Magnesium chloride, hexahydrate
(b) Sodium chloride
(c) Potassium chloride
(d) Sodium phosphate, dibasic, anhydrous
(e) Sodium sulfate, anhydrous
(f) Calcium chloride, dihydrate
(g) Sodium acetate, trihydrate
(h) Sodium bicarbonate
(i) Sodium citrate, dihydrate

Concentration $(g / 1)$

0.203

6.019

0.298

0.142

0.071

0.368

0.953

2.604

0.097

The effluent from the dissolution chamber was collected in $20 \mathrm{mi}$ aliquots in polyethylene bags. These samples were taken continuously for approximately 9 hours. Thereafter, one or two samples were taken every 24 hours for roughly 28 days. 


\section{ANALYSES:}

The respirable aerosol samples that were placed in the dissolution chamber were first analyzed for total uranium oxide by a gross gamma technique. Gross gamma monitors the amount of gamma photons that are emitted from the sample. These gamma photons can be standardized to determine the mass of uranium by comparing the counting rate of an unknown mass to that of a standard (known mass) of identical composition and geometry. ${ }^{(30)}$ This was accomplished by producing standards from the bulk samples obtained from Elder's(4) sti'A. A portion of these samples were purified to eliminate all metals u...er then uranium by a procedure developed at Los Alamos National Laboratory. ${ }^{(31)}$ These purified uranium samples were then used as standards in the gross gamma analysis. This analytical procedure could not be applied to the multiple liquid samples obtained during the dissolution experiment.

The samples generated from the dissolution study were analyzed for oxidized DU concentration by a delayed neutron (DN) technique. This technique measures the amount of ${ }^{235} \mathrm{U}$ in the sample, which can be related to the total mass of uranium oxide in National Bureau of Standards (NBS) reference standards. To determine the total mass of uranium in the oxidized DU samples it was necessary to determine the ratio of ${ }^{235} U$ in the oxidized oU samples relative to the mass of ${ }^{235} U$ in the NBS reference standards. The ${ }^{235} \mathrm{U}$ content in the oxidized DU samples was 
determined by isotopic analysis, while the ${ }^{235} u$ content of the standard reference material was supplied by the NBS. (25) The DN technique and the isotopic analysis are discussed further in the following paragraphs.

The DN technique involves counting the delayed neutrons resulting from fission of uranium after irradiation by thermal neutrons in a nuclear reactor. (25) The production of delayed neutrons is proportional to the ${ }^{235} \mathrm{U}$ concentration in the sample; consequently, the data can be standardized by comparing counts of delayed neutrons from an unkown ${ }^{235} U$ concentration to that of counts from known ${ }^{235} U$ concentrations. The technique for subjecting the samples to thermal neutrons and counting of the subsequent delayed neutrons followed the procedure outlined by Ide. (25) The analys is was carried out at the Los Alamo: National Laboratory Omega West Reactor and the equipment for this analys is was developed at the Laboratory.

The isotopic composition of the oxidized ou samples were determined by thermal ionization mass spectrometry. The analys is was carried out in the manner prescribed in the Los Alamos National Laboratory Quality Assurance Document. (31) The uranium samples were dissolved in $15.7 \mathrm{M} \mathrm{HNO}_{3}$. This solution was then fumed to dryness to expel chloride and any organic residues. A 
solution of approximately $0.2 \mu \mathrm{g} / \mu \mathrm{L}$ in uranium concentration was prepared by dissolving the fumed uranium residue in $2 \mathrm{M}$ $\mathrm{HNO}_{3}$. A volume of $\mathrm{T \mu L}$ of this solution was vaporized on a tantalum ribbon sample filament to produce uranium oxide. The sample filament was then analyzed by Mass Spectrometry for the atom percent abundances of uranium isotopes. 


\section{RESULTS}

The experiment measured the quantity of DU that dissolved as a function of time. This information was analyzed by a computer program written for this experiment, which developed cumulative plots of mass fraction remaining $\left(M / M_{0}\right)$ vs time (Figures 8 and 9) and calculated a dissolution rate $\left(\lambda^{\prime}\right)$ for each sample generated from the dissolution study. A complete listing of the computer program is given in Appendix B.

In Figures 8 and 9 the fractions of ou remaining were calculated by determining the cumulative fraction of ou that dissolved after each $20 \mathrm{ml}$ sample was obtained from the dissolution experiment. The cumulative fraction dissolved [CFD(i)] for the ith sample was obtained by the following formula:

$$
C F D(i)=\frac{M_{g}(i)}{M_{0}}
$$

where: $M_{g}=$ Mass of OU dissolved between sample $i$ and i-1(extrapolated from mass of oxidized DU dissolved in 20 minute sample).

$M_{0}=$ original mass of oxidized $D U$ on the filter.

The fraction remaining $[F R(i)]$ was then calculated as follows:

$$
F R(i)=i-C F O(i)
$$

This value was then plotted against the time at which the sample was taken relative to the start of the experiment. 
FRACTION REMAINING $\left(M / M_{0}\right)$

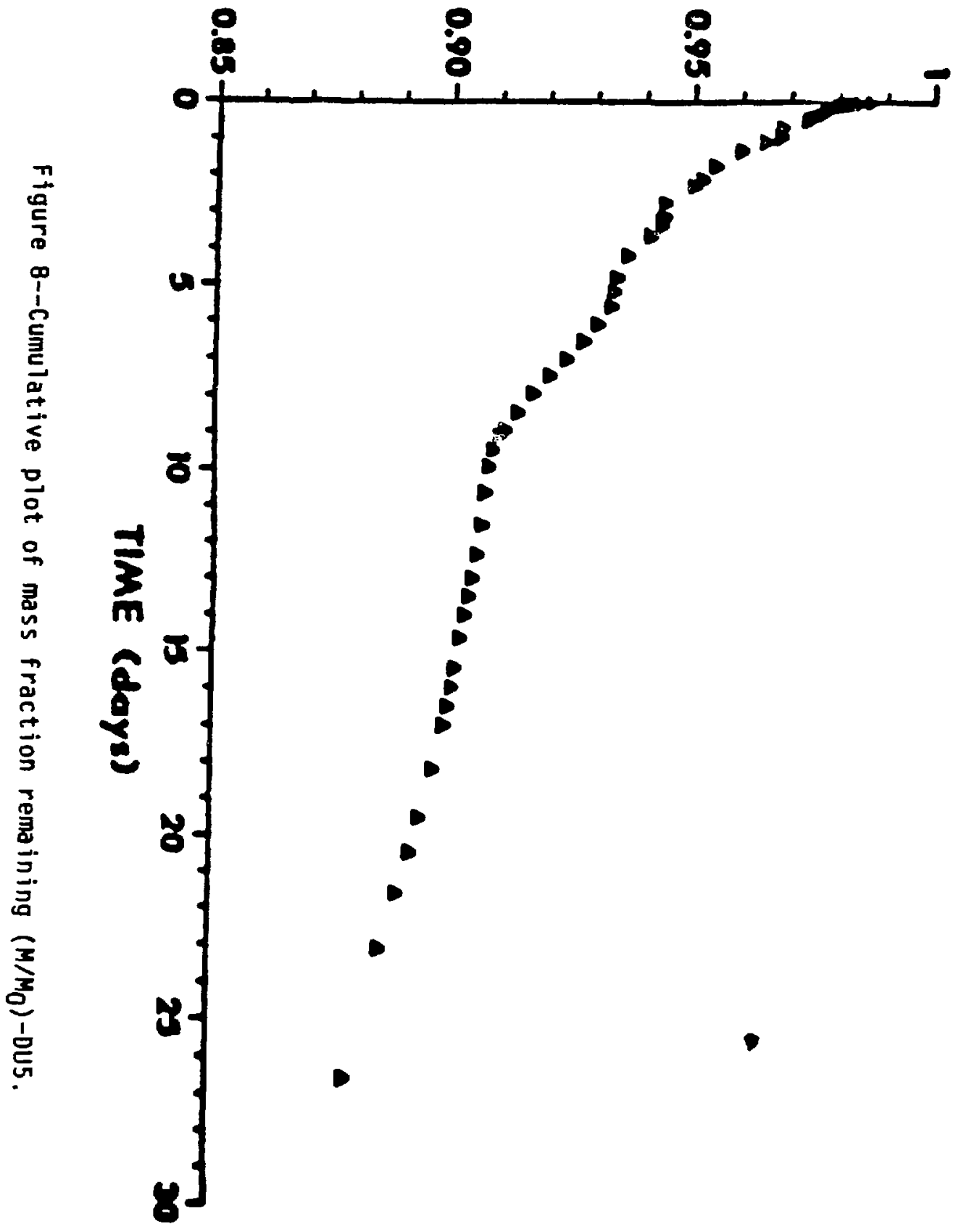




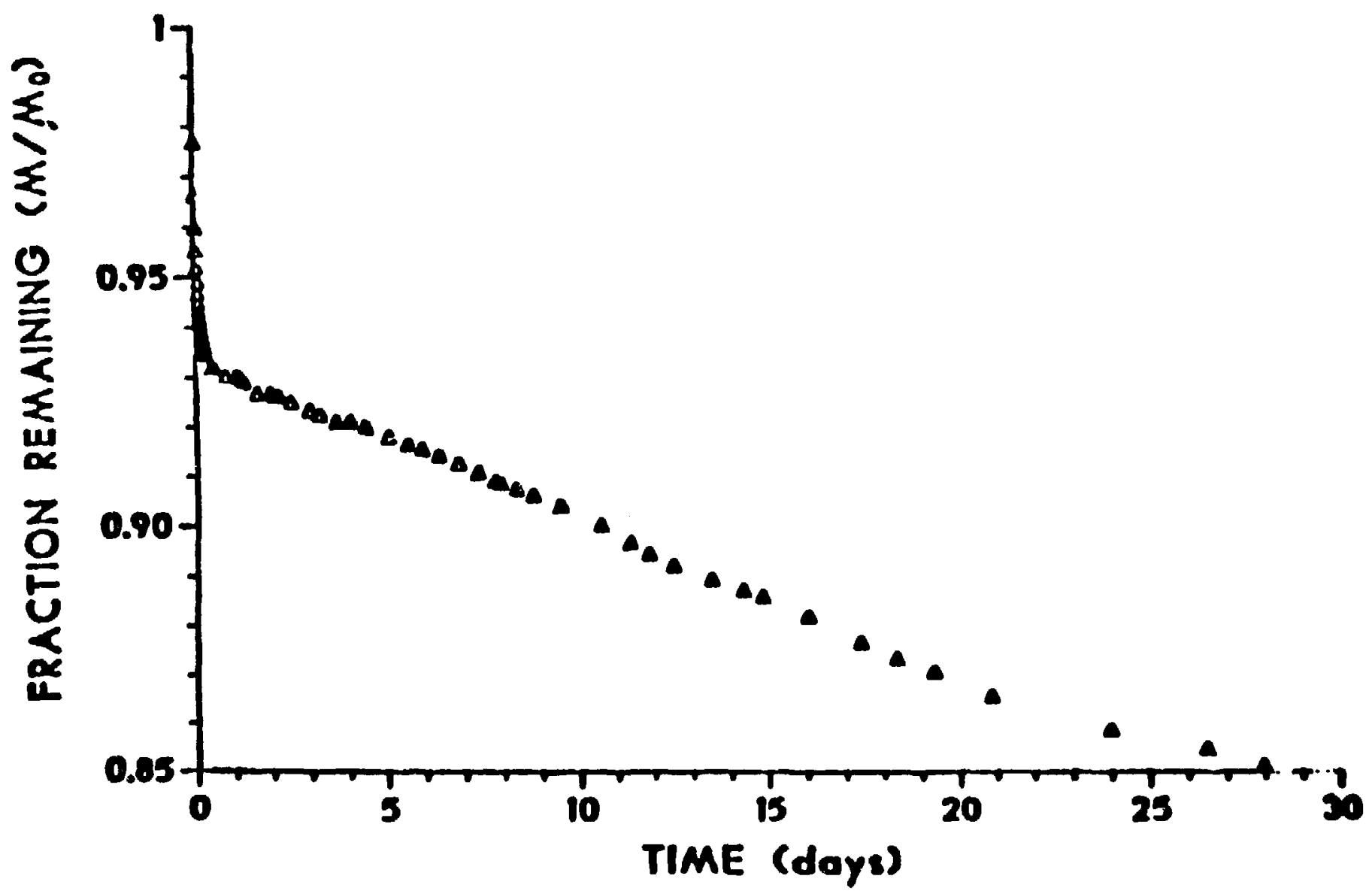

Figure 9--Cumulative plot of mass fraction remaining (M/MO)-DUg. 
Since the calculated fractions of DU remaining shown in Figures 8 and 9 were particularly high for ten days for DU5 and one day for DU9, as is typical among in-vitro dissolution studies, $(9,11,22)$ this data was not used in determining the ou dissolution rates. The dissolution rates were calculated from the data occurring after this initial dissolution phase. Specifically the dissolution rate for DU5 and DU9 were determined from the data generated after 240 hours and 209 hours, respectiveiy. A complete explanation of why this initial increase was excluded is given in the discussion section.

According to Mercer, ${ }^{(3)}$ a dissolution rate can be obtained from Figures 8 and 9 by fitting an exponential to the data occurring after the initial phase, with the slope of the exponential equaling the dissolution rate $\left(\lambda^{\prime}\right)$. This relationship was discussed in the Literature Review and is expressed mathematically by Equation (11). For statistical reasons this method was not directly used to determine a dissolution rate for DU5 and DU9. The cumulative plots (Figures 8 and 9) were not used to determine the dissolution rate because they propagate error throughout the data. Each data point was determined from a cumulative sum (Equation (13): consequently, each data point is affected by the previous data.

Instead, an estimate of the overall dissolution rate for Du5 and DU9 was calculated from each data point occurring after 240 hours and 209 hours, respectively. This was accomplished by 
obtaining an equation that would define the rate of dissolution measured in each $20 \mathrm{ml}$ sample generated from the dissolution study. From the differential of Equation (10) (with $\lambda^{\prime}$ replacing $\lambda_{1} S_{p} K$ ) it is clear this rate of dissolution is equal to

$$
d M / d t=-\lambda^{\prime} M
$$

where: $M=$ the mass of material undissolved at time $(t)$

$$
\lambda^{\prime}=\text { the dissolution rate. }
$$

Dividing both sides of the equation by $M$ gives

$$
(d M / d t) / M=-\lambda^{\prime}
$$

Equation (15) expresses, that the fraction of the remaining . material dissolved per unit time is a constant, equal to the dissolution rate $\left(\lambda^{\prime}\right)$.

The $\lambda^{\prime}$ in Equation (15) is the same constant proposed by Mercer ${ }^{(3)}$ (Equation 11).

Tables IV and $V$ list the dissolution rates calculated for each sample generated from the dissolution experiment. The formula, which was based on Equation (16), that was used to calculate the dissolution rates in Tables IV and $V$ is given below:

$$
\lambda^{\prime}(i) \text { day }^{-1}=\frac{m g^{(i)}}{F R(i) \times M_{0}} \times \frac{1440 \text { minutes/day }}{\Delta T}
$$

where: $\Delta T=$ the time interval in minutes in which the sample was taken.

$\lambda^{\prime}=$ the dissolution rate in units of $\operatorname{day}^{-1}$, and $F R(i)$

$x M_{0}$ the mass of material undissolved at time $(t)=M$. $\mathrm{m}_{\mathrm{g}}$ = the mass of DU dissolved in each 20 minute sample. 
TABLE IV

Calculated Dissolution Rate for Each $20 \mathrm{ml}$ Sample Du5

\begin{tabular}{|c|c|c|c|}
\hline $\begin{array}{l}\text { *T ime } \\
\text { HRS:MIN }\end{array}$ & $\begin{array}{l}\text { Dissolution } \\
\text { Rate }\left(\lambda^{\prime} \text { day-1) }\right.\end{array}$ & $\begin{array}{l}\text { *T ime } \\
\text { HRS:MIN }\end{array}$ & $\begin{array}{l}\text { Dissolution } \\
\text { Rate }\left(\lambda^{\prime} \text { day- }\right)\end{array}$ \\
\hline $\begin{array}{c}0: 09 \\
0: 30 \\
0: 49 \\
1: 09 \\
1: 29 \\
1: 49 \\
2: 09 \\
2: 30 \\
2: 50 \\
3: 10 \\
3: 30 \\
3: 50 \\
4: 10 \\
4: 30 \\
4: 50 \\
5: 30 \\
5: 50 \\
6: 10 \\
6: 30 \\
6: 50 \\
7: 10 \\
7: 30 \\
8: 10 \\
8: 30 \\
8: 50 \\
9: 10 \\
9: 30 \\
9: 50 \\
10: 10 \\
10: 30 \\
10: 50 \\
11: 10 \\
21: 17 \\
21: 37 \\
21: 57 \\
28: 19 \\
34: 20 \\
48: 33 \\
51: 49\end{array}$ & $\begin{array}{l}.9857 \\
.1606 \\
.0770 \\
.0587 \\
.0562 \\
.0508 \\
.0418 \\
.0335 \\
.0219 \\
.0227 \\
.0243 \\
.0201 \\
.0100 \\
.0995 \\
.0907 \\
.0398 \\
.0302 \\
.0265 \\
.0234 \\
.0205 \\
.0196 \\
.0193 \\
.0343 \\
.0215 \\
.0237 \\
.0224 \\
.0208 \\
.0200 \\
.0202 \\
.0206 \\
.0196 \\
.0188 \\
.0289 \\
.0178 \\
.0200 \\
.0243 \\
.0139 \\
.0119 \\
.0030\end{array}$ & $\begin{array}{c}57: 36 \\
74: 34 \\
74: 54 \\
80: 01 \\
80: 21 \\
94: 19 \\
103: 36 \\
107: 09 \\
124: 03 \\
124: 23 \\
125: 03 \\
143: 54 \\
148: 15 \\
166: 49 \\
171: 18 \\
187: 25 \\
194: 54 \\
212: 19 \\
217: 29 \\
219: 34 \\
235: 51 \\
240: 38 \\
269: 30 \\
284: 05 \\
308: 40 \\
315: 19 \\
331: 44 \\
339: 14 \\
362: 10 \\
379: 12 \\
386: 24 \\
403: 14 \\
410: 49 \\
460: 47 \\
475: 04 \\
506: 09 \\
530: 14 \\
578: 04 \\
698: 26\end{array}$ & $\begin{array}{l}.0161 \\
.0091 \\
.0057 \\
.0061 \\
.0057 \\
.0104 \\
.0318 \\
.0059 \\
.0043 \\
.0015 \\
.0019 \\
.0006 \\
.0110 \\
.0013 \\
.0133 \\
.0028 \\
.0107 \\
.0011 \\
.0104 \\
.0045 \\
.0020 \\
.0016 \\
.0008 \\
.0002 \\
.0021 \\
.0011 \\
.0013 \\
.0018 \\
.0010 \\
.0012 \\
.0009 \\
.0020 \\
.0014 \\
.0022 \\
.0017 \\
.0020 \\
.0025 \\
.0023 \\
.0018\end{array}$ \\
\hline
\end{tabular}

*Time denotes the elapsed time from the start of the experiment to when the sample was taken. 
TABLE $V$

Calculated Dissolution Rate for Each $20 \mathrm{ml}$ Sample Dug

\begin{tabular}{|c|c|c|c|}
\hline $\begin{array}{c}\text { *Time } \\
\text { HRS:MIN }\end{array}$ & $\begin{array}{l}\text { Dissolution } \\
\text { Rate }\left(\lambda^{\prime} \text { day }-7\right)\end{array}$ & $\begin{array}{c}\text { *Time } \\
\text { HRS:MIN }\end{array}$ & $\begin{array}{l}\text { Dissolution } \\
\text { Rate }\left(\lambda^{\prime} \text { day-1) }\right.\end{array}$ \\
\hline $\begin{array}{r}0: 09 \\
0: 30 \\
0: 49 \\
1: 09 \\
1: 29 \\
1: 49 \\
2: 09 \\
2: 30 \\
2: 49 \\
3: 09 \\
3: 30 \\
3: 49 \\
4: 09 \\
4: 29 \\
4: 49 \\
5: 09 \\
5: 29 \\
5: 49 \\
6: 09 \\
6: 29 \\
11: 15 \\
11: 34 \\
24: 41 \\
25: 01 \\
29: 06 \\
30: 00 \\
46: 05 \\
46: 25 \\
51: 30 \\
51: 50 \\
66: 24\end{array}$ & $\begin{array}{l}1.7085 \\
.7865 \\
.4725 \\
.3342 \\
.2520 \\
.2084 \\
.7680 \\
.1431 \\
.1206 \\
.1002 \\
.0909 \\
.0784 \\
.0704 \\
.0650 \\
.0531 \\
.0515 \\
.0466 \\
.0398 \\
.0391 \\
.0329 \\
.0142 \\
.0049 \\
.0053 \\
.0058 \\
.0056 \\
.0073 \\
.0053 \\
.0047 \\
.0053 \\
.0040 \\
.0039\end{array}$ & $\begin{array}{r}75: 39 \\
79: 12 \\
96: 12 \\
96: 32 \\
96: 52 \\
115: 40 \\
127: 00 \\
139: 34 \\
144: 41 \\
160: 47 \\
168: 16 \\
185: 45 \\
189: 52 \\
192: 57 \\
209: 10 \\
213: 54 \\
242: 48 \\
264: 32 \\
280: 57 \\
288: 27 \\
312: 00 \\
335: 17 \\
352: 07 \\
359: 42 \\
410: 16 \\
424: 27 \\
454: 32 \\
472: 37 \\
526: 27 \\
622: 54 \\
646: 35 \\
694: 36\end{array}$ & $\begin{array}{l}.0027 \\
.0038 \\
.0032 \\
.0028 \\
.0030 \\
.0024 \\
.0038 \\
.0025 \\
.0029 \\
.0029 \\
.0036 \\
.0038 \\
.0034 \\
.0028 \\
.0028 \\
.0027 \\
.0032 \\
.0042 \\
.0048 \\
.0045 \\
.0027 \\
.0035 \\
.0014 \\
.0037 \\
.0032 \\
.0047 \\
.0023 \\
.0032 \\
.0033 \\
.0012 \\
.0019 \\
.0028\end{array}$ \\
\hline
\end{tabular}

*Time denotes the elapsed time from the start of the experiment to when the sample was taken. 
According to Equation (15), the $\lambda$ 's calculated after 240 hours and 209 hours for DU5 and DU9 respectively, should approximate a constant value. To support this assismption statistical analyses on the dissolution rates were performed to determine if an average value of the dissolution rates could be used to report the dissolution rate for DU5 and DUg. First, a linear regression analysis was used to fit a straight line to the dissolution rates and their corresponding sample times. These plots are shown in Figures 10 and 11.

Secondiy, a hypothesis was tested to determine if the slopes obtained from the regressions were significantly different from zero. To test the hypothesis a ' $t$ ' statistic (Table VI) based on the differences of the two slopes was used. The ' $t$ ' statistic has a $t$ distribution with $n-2$ degrees of freedom and the critical regions for this statistic are summarized in Table VI. The formula used in testing the hypothesis was obtained from ostle. (32) The significance level, which indicates the probability of a true hypothesis being rejected was set at .05 . The null hypothesis (that the slopes are not significantly different from zero) is accepted when significance levels are less than .05. (32)

Statistical analysis of the data showed that the slopes were not significantly different from zero (Table VI). The values calculated from the $t$ statistic fell well inside the critical regions (Table VI). By accepting the null hypothesis, it was concluded that the dissolution rate $\left(\lambda^{\prime}\right)$ for DUS and DUg did not vary as a function of time. Thus, an average value of the 


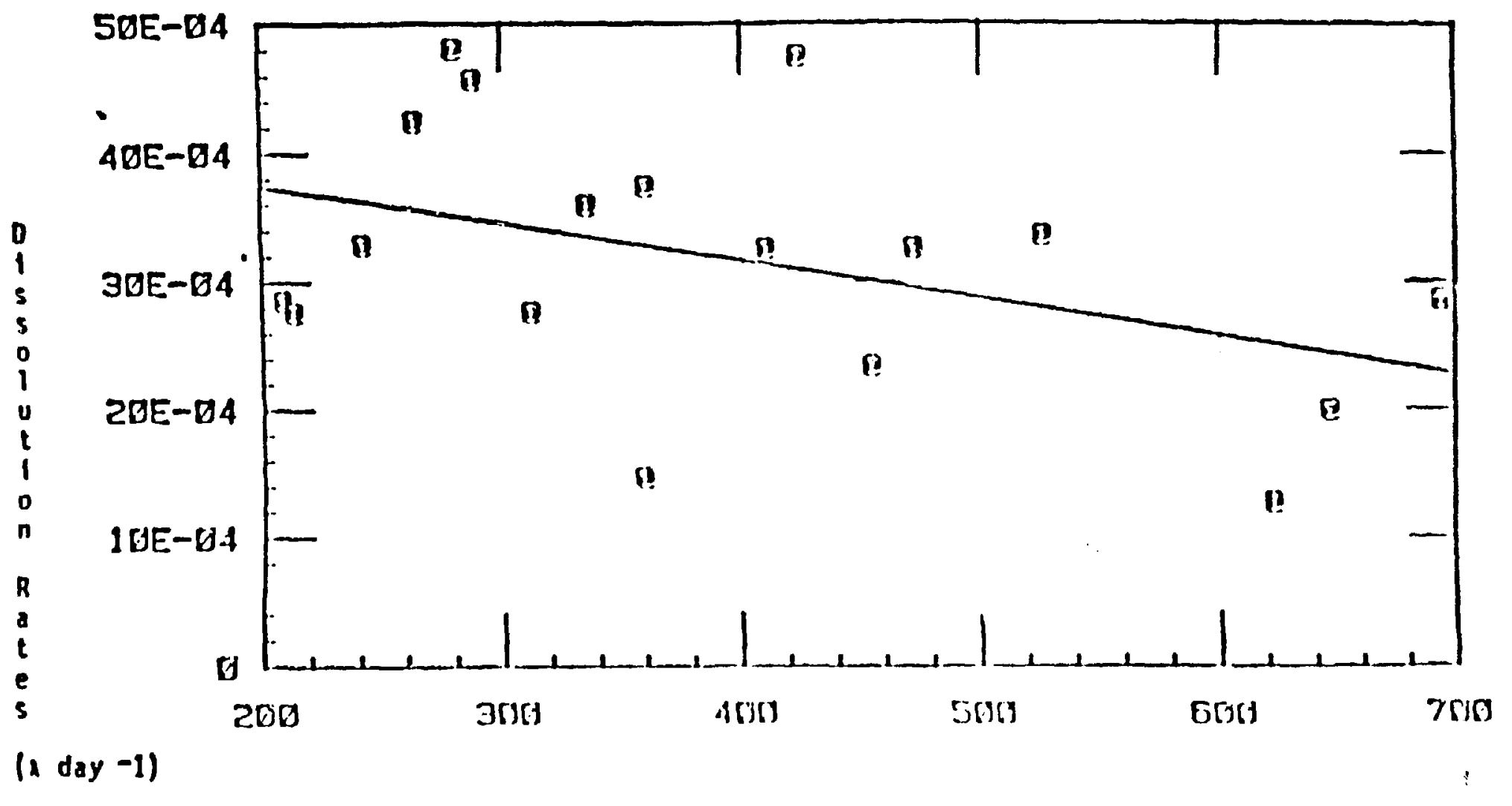

TIIIF. (IInIIns)

Figure 10--Linear regression analysis on the dissolution rates calculated for samples taken after 240 hours (Table 4) - DU5. 


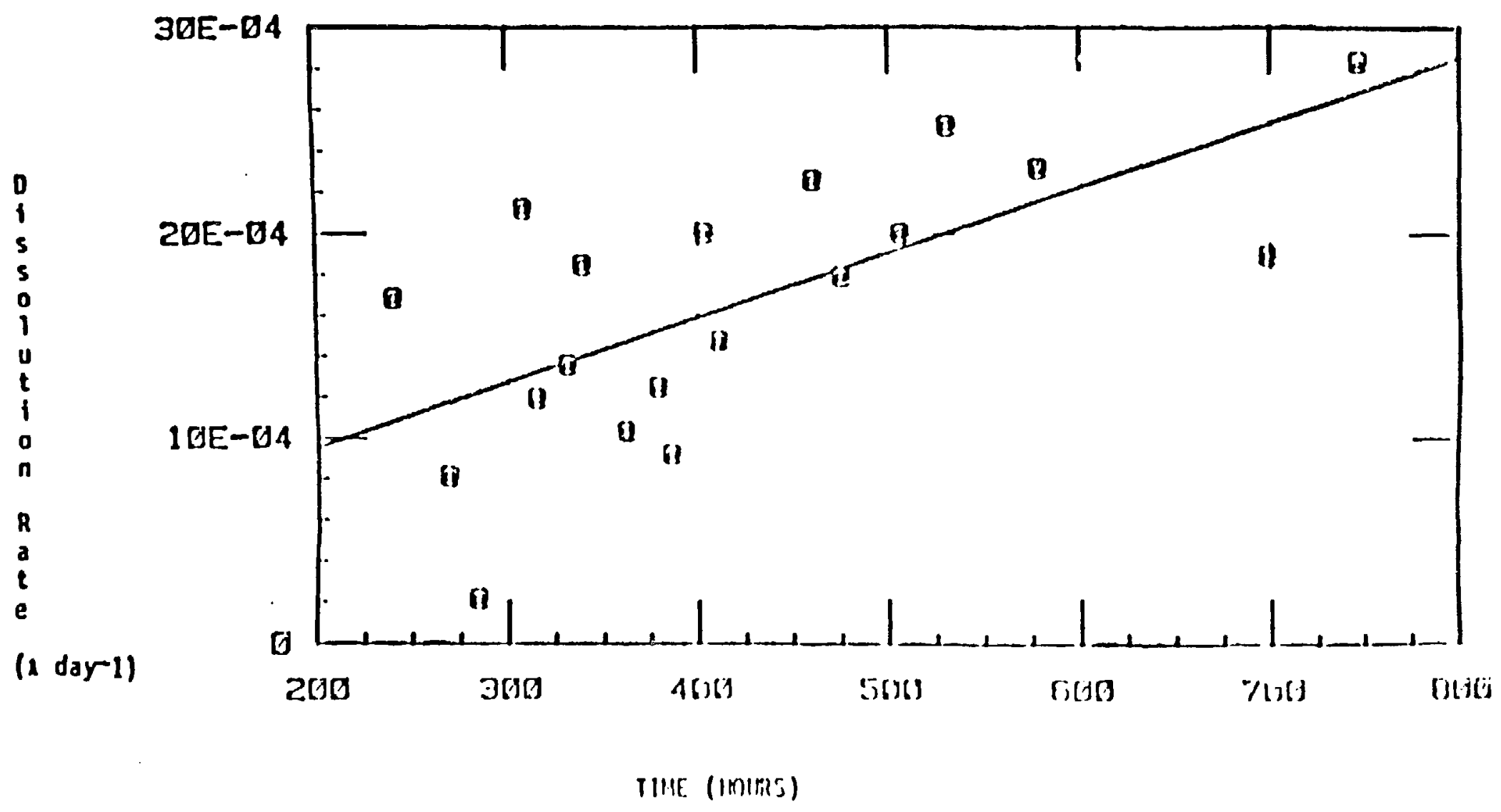

Figure 11--Linear regression analysis on the dissolution rates calculated for samples taken after 240 hours (Table 5) - DU9. 
TABLE VI

Test of Hypothesis $\left(B_{0}=0\right)$ for Slopes Obtained From Linear Regressions (Figs. 8 and 9 )

\begin{tabular}{|c|c|c|c|c|c|}
\hline & $\begin{array}{l}\text { Slopes } \\
\left(B_{0}\right)^{\circ}\end{array}$ & $\begin{array}{l}\text { Standard Error } \\
\text { of Estimate } \\
\left(S_{b_{0}}\right)\end{array}$ & $\begin{array}{l}\text { Hypothes is } \\
\text { (H) }\end{array}$ & Test Statistic & $\begin{array}{l}\text { Critical Region } \\
\text { for a two-s lided } \\
\text { Alternative }\end{array}$ \\
\hline W-5 & $3.17 \times 10^{-6}$ & $4.97 \times 10^{-3}$ & $H_{0}: B_{0}=0$ & $\begin{array}{l}t=\left(B_{0}-0\right) / s_{b_{0}} \\
-6.38 \times 10^{-3}\end{array}$ & $\begin{array}{l}{[t]>t(1-a / 2)(n-2)} \\
{[t]>t .975,17=2.110}\end{array}$ \\
\hline ous & $2.933 \times 10^{-6}$ & $9.608 \times 10^{-4}$ & $H_{0}: B_{0}=0$ & $\begin{array}{l}t=\left(B_{0}-0\right) / s_{b_{0}} \\
-3.05 \times 10^{-3}\end{array}$ & $\begin{array}{l}{[t]>t(1-12)(n-2)} \\
{[t]>t .975,16-2.120}\end{array}$ \\
\hline
\end{tabular}


dissolution rates could be used to report the dissolution rate for DU5 and DU9. An average dissolution rate and a $97.5 x$ confidence interval on that average value was obtained for DUs and oug from the dissolution rates calculated after 240 hours and 209 hours. respectively. The results of these calculations are listed in Table VII.

\section{TABLE VII}

Determination of Average Dissolution Rate and a 97.5 Percent Confidence Interval on That Average for DUJ5 and Dug

DU5

Dissolution Rates $\left(\lambda^{\prime}\right.$ day-l)

*after 240 hours

\begin{tabular}{llll}
$\begin{array}{l}\text { Time } \\
\text { HR:MIN }\end{array}$ & $\begin{array}{l}\text { Dissolution } \\
\text { Rate( } \lambda^{\prime} \text { day-1) }\end{array}$ & $\begin{array}{l}\text { Time } \\
\text { HR:MIN }\end{array}$ & $\begin{array}{l}\text { Dissolution } \\
\text { Rate }\left(\lambda^{\prime} \text { day-1) }\right.\end{array}$ \\
\hline $240: 38$ & .0016 & $209: 10$ & .0028 \\
$269: 30$ & .0008 & $213: 54$ & .0027 \\
$284: 05$ & .0002 & $242: 48$ & .0032 \\
$308: 40$ & .0021 & $264: 32$ & .0042 \\
$315: 19$ & .0017 & $280: 57$ & .0048 \\
$331: 44$ & .0013 & $288: 27$ & .0045 \\
$339: 14$ & .0018 & $312: 00$ & .0027 \\
$362: 10$ & .0010 & $335: 17$ & .0035 \\
$379: 12$ & .0012 & $352: 07$ & .0014 \\
$386: 24$ & .0009 & $359: 42$ & .0037 \\
$403: 14$ & .0020 & $410: 16$ & .0032 \\
$410: 49$ & .0014 & $424: 27$ & .0047 \\
$460: 47$ & .0022 & $454: 32$ & .0023 \\
$475: 04$ & .0017 & $472: 37$ & .0032 \\
$506: 09$ & .0020 & $526: 27$ & .0033 \\
$530: 14$ & .0025 & $622: 54$ & .0012 \\
$578: 04$ & .0023 & $646: 35$ & .0019 \\
$698: 26$ & .0018 & $694: 36$ & .0028 \\
& & & \\
\hline$\lambda^{\prime}=1.7 \times 10^{-3}=3.2 \times 10^{-4}$ & & & \\
& & &
\end{tabular}

*Values for DU-5 and DU-9 were taken from Tables $\underline{4}$ and $\underline{5}$ respectively. 
Results of the isotopic analysis and Gross Gamma analysis are summarized in Table vIII. From the isotopic analysis, the ratio of ${ }^{235} \mathrm{U}$ in the oU samples relative to the mass of ${ }^{235} \mathrm{U}$ in the NBS reference standards used in the delayed neutron technique was determined. According to the National Bureau of Standards, their reference standards $\left(\mathrm{U}_{3} \mathrm{O}_{8}\right)$ are $.72 \%$ abundant in ${ }^{235} \mathrm{u}^{(25)}$, while isotopic analysis determined that OU5 and DUg were both .20\% abundant in ${ }^{235} \mathrm{U}$. This results in a ${ }^{235} \mathrm{U}$ ratio between the NBS standards and the DU samples of 3.6 . This ratio was then used to prevare a calibration curve relating DN counts measured during analysis of the DU samples to the total mass of DU oxide in these samples.

The Gross Gamma technique was used to analyze the filters placed in the flowpast dissolution chamber for total uranium content prior to the dissolution study. The values obtained were then used as $\boldsymbol{M}_{\mathbf{g}}$ in Equation (16).

The average dissolution rate for DU5 and DUg were used in Cuddihy's lung clearance model to predict the regional fractions of oxidized bU deposited in the pulmonary region that would be cleared via the following pathways; lung to lymph, lung to GI, and lung to blood. These regional fractions were calculated by Equation (8) and the results are shown in Table IX. The dissolution rate for DU5 and DUg $\left(\lambda^{\prime}=K_{3}=7.7 \times 10^{-3}\right.$ and $\lambda^{\prime}=K_{3}=3.2 \times 10^{-3}$, were used for pulmonary to blood clearance.. A clearance rate of $0.0001 /$ day between the pulmonary and lymph nodes $\left(x_{2}\right)$ 


\section{TABLE VIII}

Results from Isotopic and Gross Gamma Analys is

\begin{tabular}{|c|c|c|}
\cline { 2 - 3 } & $\begin{array}{c}\text { Isotopic Analysis } \\
\text { (atom percent abundant in 235u) }\end{array}$ & $\begin{array}{c}\text { Gross Gamma } \\
\text { (mass of uranium oxide) }\end{array}$ \\
\hline DU5 & $0.20 \pm .002$ & $0.01307(\mathrm{~g})$ \\
\hline Dug & $0.20 \pm .002$ & $0.01428(\mathrm{~g})$ \\
\hline
\end{tabular}


was taken from a report by Thomas $(10)$ and a clearance rate of $0.0014 /$ day between the pulmonary and GI $\left(K_{1}\right)$ was obtained from ICRP 30. (20) These clearance rates were assumed to be the sane for both ous and DUg.

Predictions of the above regional fractions were also obtained from the ICRP Task Group Model on Lung Oynamics. The values for these predictions were obtained from the ICRP $30^{(20)}$ for Class $Y$ compounds. Both DU5 and DU9 were determined by the ICRP Task Group classification scheme to be $\gamma$ compounds by their characterstics dissolution half lifes (for further detail refer to the Discussion). A summary of the ICRP Task Group predictions are also given in Table IX.

Due to equipjment faìlure specific surface area anaylses were not obtained. Consequently, the dissolution rate constant $(X)$ in Equation (11) was not determined for DU5 and DU9. The main thrust of this thesis was to compare predictions from two biomathematical models based on the dissolution rates of DU5 and DU9, which were measured directly. Thus, the absence of the dissolution rate constants has little impact on this thesis. 
TABLE IX

Predictions by the Task Group Model and Cuddihy's Model. The regional fractions predicted by the Task Group model were obtained from ICRP 30.(20) However, these values were corrected to reflect the long-term clearance. The short-term clearance for Gl was not reported.

\begin{tabular}{|c|c|c|c|c|}
\hline \multirow[t]{2}{*}{ Clearance Pathways } & \multicolumn{2}{|c|}{ Task Group Model } & \multicolumn{2}{|c|}{ Cuddihy's Model } \\
\hline & DU-5 & DU-9 & OU-5 & DU-9 \\
\hline Lung to Blood & .08 & .08 & .53 & .68 \\
\hline Lung to GI & .67 & .67 & .44 & .30 \\
\hline Lung to lymph & .25 & .25 & .03 & .02 \\
\hline
\end{tabular}




\section{DISCUSSION}

For both DU5 and DU9, high rates of dissolution were observed initially. From the cumulative piots (Figures 8 and 9 ) it can be seen that the fraction remaining changes rapidly for approximately ten days for DU5 and for one day for OU9. This initial dissolution increase as mentioned in the Results section is typical among in-vitro dissolution studies. $(9,11,22)$ However, there has been no firm conclusion as to its exact cause. It is common practice to calculate the dissolution rate from the data obtained after this initial dissolution has taken place. $(9,11,22)$ The exclusion of this data appears to be valid since in-vitro dissolution rates obtained from the data occurring after this initial dissolution has been shown to agree (within a factor of two) with in-vivo dissolution rates. $(9,22)$

In this experiment, the dissolution rate for DU5 and DU9 were generated from data obtained after 240 hours and 209 hours, respectively. These time frames were chosen because they excluded the data from the initial dissolution and they allowed for approximately an equal number of samples for both DU5 and DU9 for determining the dissolution rate.

The dissolution rates obtained for DU5 and DUg (Table VII) were used in Cuddihy's lung clearance mode ${ }^{(2)}$ to predict the regional fractions that would be cleared from the pulmonary region 
by the various pathways following an inhalation exposure to oxidized DU. These regional fractions were then compared in Table IX to regional fractions predicted from the ICRP Task Group mode1. (1) As stated in the Results, Class Y parameters defined by the ICRP Task Group on Lung dynamics were used for both DU5 and DU9. Class $Y$ is used to describe the most avidly retained substances which are expected to manifest maximal biological half-times ranging from 6 months to several years. (1) The half-times for DU5 and DU9 were determined to be 407 and 217 days respectively $\left(t_{1 / 2}=\ln 2 / \lambda^{\prime}\right)$. Since both DU5 and DU9 fell into the $Y$ classification, the ICRP Task Group monel would predict the same regional fractions for DU5 and DU9. A summary of the predictions by the ICRP Task Group model and Cuddihy's model are given in Table $I X$.

As can be seen from the data presented in Table IX the regional fractions cleared from the pulmonary region predicted by Cuddihy's model differed considerably from the values predicted by the ICRP Task Group. For example, Cuddihy's model predicted regional clearances of $53 \%$ and $68 \%$ from the pulmonary region to blood for the two samples, while the ICRP Task Group predicted an 8\% clearance.

In order to draw conclusions from the above differences, a basic understanding of how both modeis interpret the pulmonary clearance environment must be attained. 
Cuddihy's model explains the clearance of particles from the pulmonary region as a dynamic system. The pulmonary region is preceived as one component in which the clearance rates of the three pathways compete for the clearance of materials deposited in this region. The derivation of Equation ( $\theta$ ) was built on this assumption.

In contrast, the ICRP Task Group views the pulmonary region as compartmentalized (Figure 1). The ICRP Task Group depicts pulmonary clearance as an environment in which clearance rates of the various pathways do not compete against each other. For example, the $25 \%$ of material deposited in the pulmonary region that is predicted by the ICRP Task Group to be cleared to the lymph system is not available for clearance by the opposing pathways. Consequently, the amount of material cleared by a pathway is not a reflection of the clearance rate for the pathway. In conversation on December 15, 1982 with Dr. Paul E. Morrow, who was chairman of the ICRP Task Group on Lung Dynamics, he expressed that the regional fractions predicted by Cuddihy's model could not be directly compared to the ICRP Task Group. However, the total amount of material deposited in the pulmonary region cleared to blood predicted by each model could be compared. The above can be determined by calculating the amount of material that will be absorbed from the GI tract and lymph system into the blood system. According to ICRP $30,{ }^{(20)} 0.2 \%$ of Class Y materials 
entering the GI tract, following inhalation, will be absorbed into the blood stream, and $90 \%$ of the material entering the lymph nodes will be cleared to blood.

Using these constants and the data in Table IX a total of lung to blood clearance was calculated for DU5 and DU9 using the ICRP Task Group Model and Cuddihy's model (CM). The following was obtained :

Total Amount of Material Deposited in the Blood

DU5

DU9

$C M .53+.002(.44)+.9(.03)=.56 \quad .68+.002(.30)+.9(.02)=.70$

ICRP .08 $+.002(.67)+.9(.25)=.31 .08+.002(.67)+.9(.25)=.31$

The numbers represent the total fraction of material deposited in the pulmonary region that would be cleared to blood as predicted by both models. 


\section{CONCLUSIONS}

The results of this study indicate that there is a substantial difference between predictions by the ICRP Task Group model and Cuddihy's lung clearance model. Cuddihy's model predicts a much larger fraction of oU cleared to blood from the pulmonary region. This has an effect of increasing the dose to the target organ because deposited material is moved more readily from lung to blood. According to the ICRP, (5) the target organ for relatively soluble oU is the kidney. Subsequently, Cuddihy's model would predict a larger dose to the kidney than would the ICRP Task Group model following an inhalation exposure. This conclusion is consistent with data collected by Parson. Parson compared a 50-yr kidney dose, as computed from the ICRP Task Group mode1, and a model based on work conducted by

Mercer. (3) He concluded that there was greater than a two-fold increase in kidney dose predicted by the model based on Mercer's work relative to the ICRP Task Group dose predictions.

The opinion of this researcher is that the major difference botween the two models is the way in which each model preceives the clearance from the pulmonary region. Cuddiny's model views the clearance as being from a single compartment while the ICRP Task Group assumes a non-interactive multi-compartment clearance. Recently, there has been a few in-vivo dissolution studies $(9,11)$ 
that suggest that Cuddihy's approach gives a fairly accurate estimate of the pulmonary clearance environment. This indicates that the single compartment approach may give a better prediction of pulmonary clearance. However, much more in-vivo data is needed to confirm this conclusion.

Since the ICRP Task Group model does not seem to be as conservative as suggested by Cuddihy's model, it should be used with caution. 


\section{RECOMMENDATIONS}

During the completion of this research it became apparent that further information was needed on the following:

1. Identification of the initial rapid dissolution rate. This initial phase is a commonly observed phenomenon in such studies. However, the cause of its origin has not been substantiated.

2. In this study the aerosols generated had a cut of $f$ diameter of 7um (BMRC criteria). It was assumed that the difference between particle size distributions of the aerosols used in this study and aerosol deposited in the pulmonary region would not affect the dissolution rate. In order to support this assumption (one made by many researchers) information is needed on what effect, if any, this presumably small difference in particle size has on the dissolution rate. 


\section{ACXNOWLEDGEMENTS}

I would like to express my appreciation to Mr. Ronald Scripsick, Mr. Marvin Tillery, Or. Sidney Soderholm, and Dr. Robert Thomas at the Los Alamos National Laboratory for their assistance in the technical preparation of this thesis. I would also like to express my appreciation to Dr. Richard Cuddihy at the Inhalation Toxicology Research Institute for his assistance in the development of this thesis. I would also like to thank Mr. Lloyd Wheat and Mr. Kevin Burgett for their help in the implementation of this experiment. A special thanks must be given to Mr. Harry Ettinger for arranging my internship at Los A lamos and for serving as my advisor during the internship. I would also like to thank Mr. William Nelson and Mr. Alan Chamberlin for their assistance in the development of the computer program. Acknowledgement should also be given to the NIOSH Support Grant No. 5-T15-0H07085-85 which funded my graduate career at Texas A \& M. Finally, I would like to express my appreciation to my committee chairman. Dr. Richard Konzen and to my committee members; Mr. Charles Gilmore, Dr. Richard Neff, and Mr. Harry Ettinger for their assistance in the preparation of this thesis. 


\section{REFERENCES}

1. Task Group on Lung Dynamics: Deposition and Retention Models for Internal Dosimetry of the Human Respiratory Tract. Health physics. 12:173-207 (1966).

2. Cuddihy, R. G.: Work Shop on Measurements and Interpretation of Actinide Accumulation by Man: Proceedings of the Snowbird Actinide Workshop, pp. 617-628, Snowbird, Utah, october 1979, (M. E. Wrenn, ed.), RO Press (198?).

3. Mercer, T. T.: On the Role of Particle Size in the Dissolution of Lung Burdens. Health Physics. 13:211-1221 (1967).

4. Elder, J. C., and M. C. Tinkle: Oxidation of Depleted Uranium Penetrators and Aerosol Dispersal at High Temperatures. Los Alamos Scientific Laboratory. Report LA-8610-MS, LOS Alamos, NM (1980).

5. International Commission on Radiological Protection (ICRP): Evaluation of Radiation Doses to Body Tissues from Internal Contamination Due to Occupational Exposure. ICRP Publication 10. Pergamon Press, New York (1966).

6. Brain, J.D., and P.A. Valberg: Models of Lung Retention Based on ICRP Task Group Report. Arch Environ Health. 28:1-11 (1974).

7. Hatch, T. F., and P. Gross, Pulmonary Deposition and Retention of Inhaled Aerosols. Pp.69-116. Academic Press, New York(1964).

B. Morrow, P. E., F. R. Gibb, and K. M. Gazioglu: A Study of Particulate Clearance From the Human Lungs. American Review of Respiratory Disease. 96:1209-1221 (1967).

9. Kanapilly, G.M., O.G. Raabe, C.T. Goth, and R.A. Chimenti: Measurement of In Vitro Dissolution of Aerosol Particles for Comparison To In Vivo Dissolution In the Lower Respiratory Tract After Inhalation. Health Physics. 24:497-507 (1973).

10. Thomas, R. G.: Transport of Relatively Insoluble Materials From Lung to Lymph Nodes. Health Physics. 14:111-117 (1968).

11. Raabe, D.G., S.V. Teague, N.L. Richardson, and L.S. Nelson: Aerodynamic and Dissolution Behavior of Fume Aerosols Produced During the Combustion of Laser Ignited Plutonium Oroplets in Air. Health Physics. 35:663-674 (1978).

12. Morrow, P. E., F. R. Gibb, and L. Johnson: Clearance of Insoluble Dust From the Lower Respiratory Tract. Health Physics. 10:543-555 (1964). 
13. Cuddihy, R. G., H. P. Russell, and W. G. Griffith: Inhalation Exposures to Barfum Aerosols: Physical, Chemical and Mathematical Analysis. Health Physics. 26:405-416 (1974).

14. Kanapilly,G.M.: Alveolar Micro-environment and its Relationship To the Retention and Transport into Blood of Aerosols Deposited in the Alevolf. Health Physics. 32:89-100 (1977).

15. Moss, O. R., and G. M. Kanapilly: Dissolution of Inhaled Aerosols. In: Generation of Aerosols. 1980, (Kdausivilleke, ed.). Ann Arbor Science Publication, Ann Arbor, Michigan $(1980)$.

16. Blauer, M. H., N. A. Dennis, and E. K. Jacqueline: Dissolution Fractions and Half-Times of Single Source Yellow Cake in Simulated Lung Fluids. Health Physics. 42:469-477 (1982).

17 Cooke, N., and F. B. Holt: The Solubility of Some Uranium Compounds in Simulated Lung Fluid. Health Physics. 27:69-77 (1974).

18. Moss, O. R.: Simulants of Lung Interstitial Fluid. Health Physics. 36:447-448 (1979).

19. Cuddihy, R. G., S. R. Gomez, and R. C. Pfleger: Inhalation Exposure of Beagle Dogs to Cerium Aerosols: Physical. Chemical and Mathematical Analysis. Health Physics. 29:257-265 (1975).

20. International Commission on Radiological Protection (ICRP): Limits for Intakes of Radionuclides by Workers. ICRP Publication 30. Oxford Press, New York(1979).

21. Newton, G. J., J. A. Stanley, and H. C. Yeh: Plutonium Containing Aerosols a Comparison of Two Industrial Mixed-Dxide Fuel Fabrication Processes. Inhalation Toxicology Research Institute Annual Report. LF-60, Albuquerque, NM. (1978).

22. Eidson, F. A., and J. A. MeWhinney: In-vitro solubility of Yellowcake Samples From Four Uranium Mills and The Implications For Bioassay Interpretation. Health Physics. 39 : 893-902 (1980).

23. Scripsick, R. C., K. C. Crist, M. I. Tillery, and S. J. Rothenburg: Dissolution of Uranium Oxide Materials. Study in Progress. Los Alamos Scientific Laboratory, Los Alamos. NH.

24. Aerosol Technology Committee: Guide for Respirable Mass Sampling. Am. Ind. Hyg. Assoc. … 33:133-137 (1970). 
25. Ide, H. H., H. O. Moss, M. M. Minor, and E. E. Campbe 11: Analysis of Uranium in Urine by Delayed Neutrons. Health Phystcs. 37:405-408 (1979).

26. Wright. B. H.: A New -feed Mechanism. J. Sc1. Instr. 27:12-15 (1975).

27. Fairchild, I. C., H. 1. Tillery, and H. J. Ettinger: Coa 1 Aerosol Research and Development. Los Alamos Scientiftc Laboratory. Report LA-6422, Los Alamos, NH (1977).

28. Allen, H. D., J. K. Brlant, D. R. Moss, E. J. Rossignol, D. D. Mahbum, L. G. Morgan, J. L. Ryan, and R. P. Turcotte: Dissolution Characteristics of LMFBR Fuel-Sodium Aerosols. Health Physics. 40:183-193 (1981).

29. Kalkwarf, D. R.: Solubllity Classification of Airborne Uranium Products from LWR-Fuel Plants. Pacific Northwest Laboratory. NURE G/CR1428 PNL-3411. Prepared for U. S. NuClear Regulatory Commission (1978).

30. Shapiro, J.: Radiation Protection A Guide for Scientist and Physlcians. 2nd Eoition, pp. 201-220, Harvard Univ. Press, Cambridge, MA. (1981).

31. Marsn. L.S.: Quality Assurance Document Analytical Chemistry. LoS Alamos National Laboratory. Document ANC-DE 1-MS-3, R4, LoS Alamos, NH. (1981).

32. Ostle, B., and R. W. Mensing: Statistics In Research. 3rd Edition, pp. 177-178, Iowa State Univ, Press, Ames, IA. (1979)

33. Parsont, M. A., W. L. Holley, and W. D. Burnett: The Effect of Particle Size on Organ Distribution of Radioactive Material Deposited in the Lungs. Health Physics. 22:143-148 (1971) 
APPENOIXA

Classification Scheme of Inorganic Compounds By ICRP 


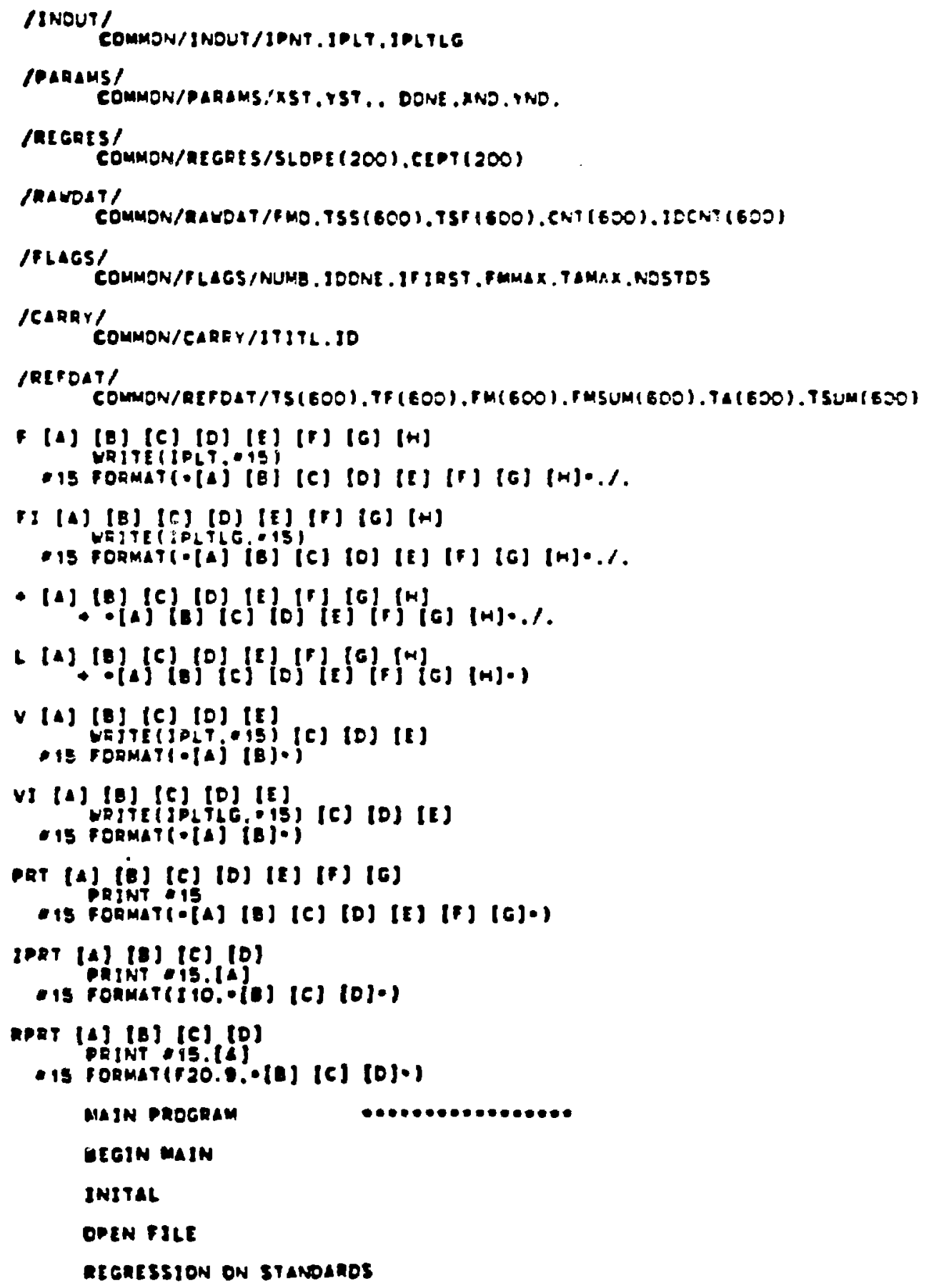




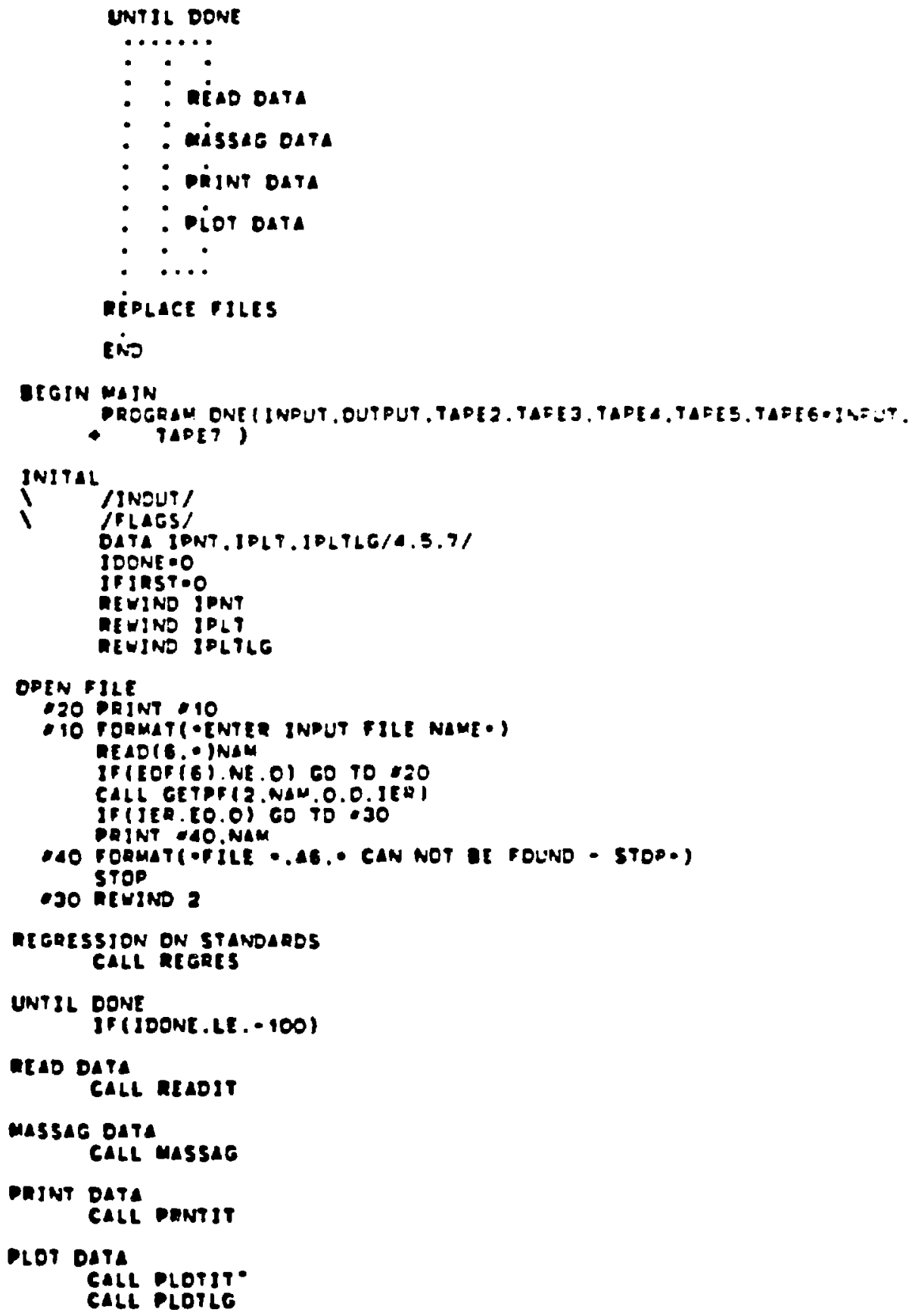




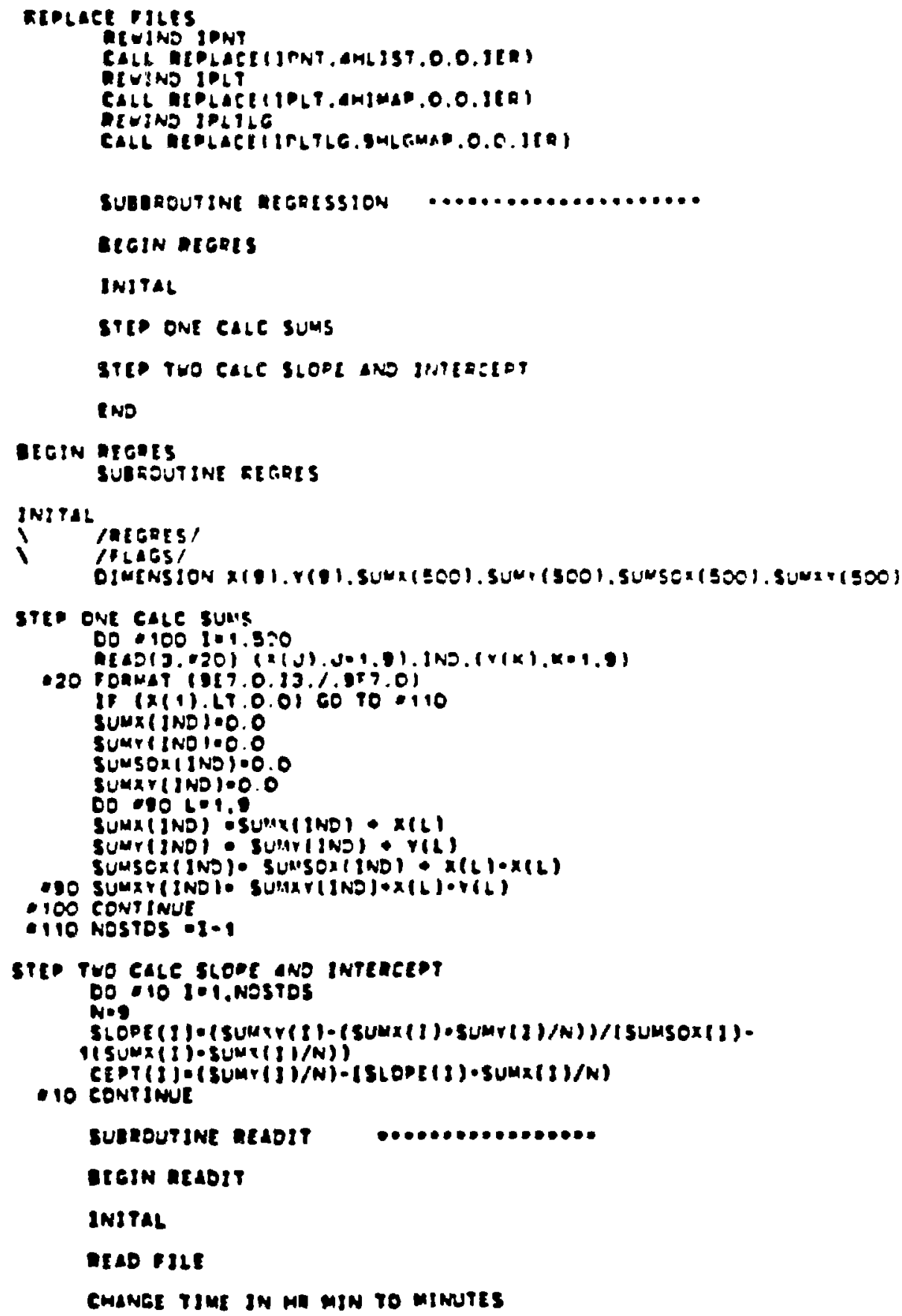




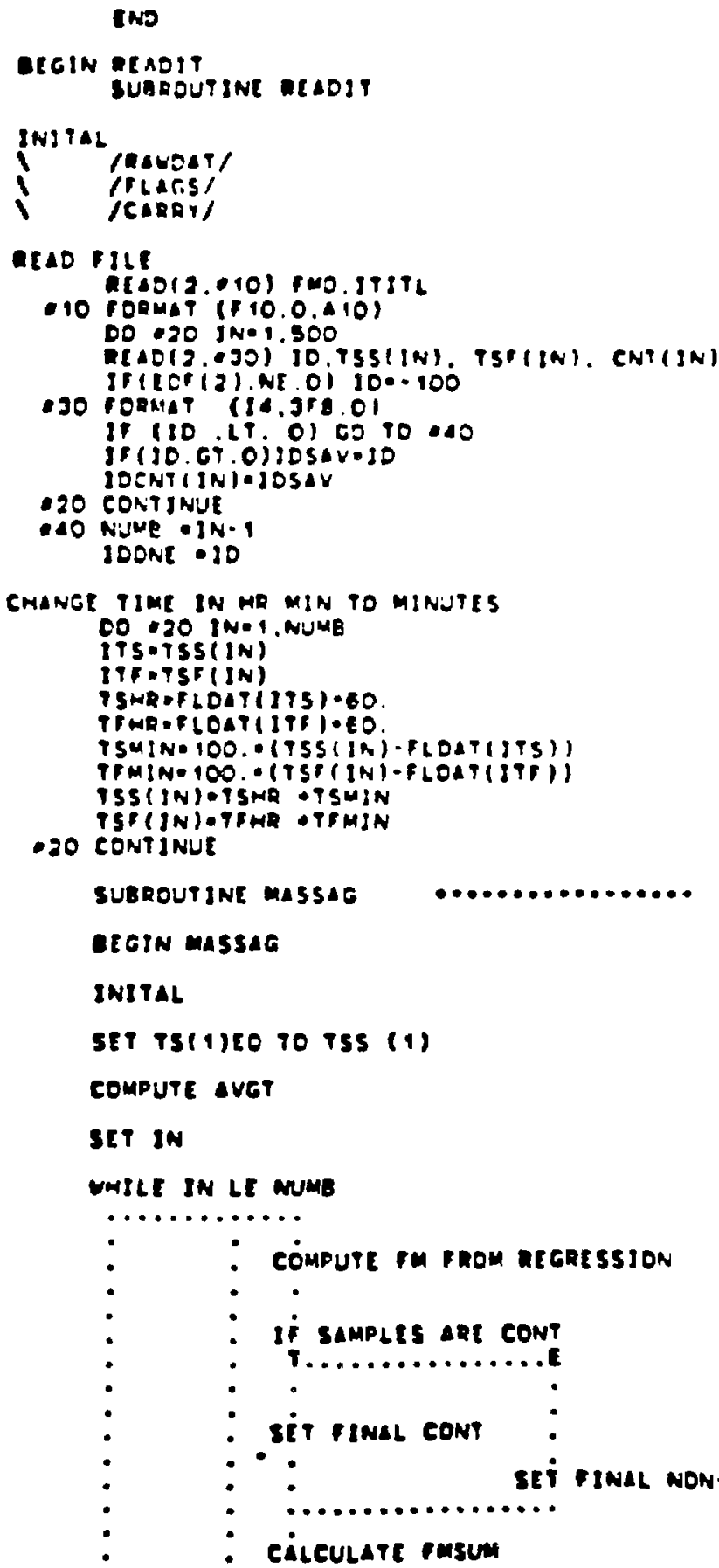




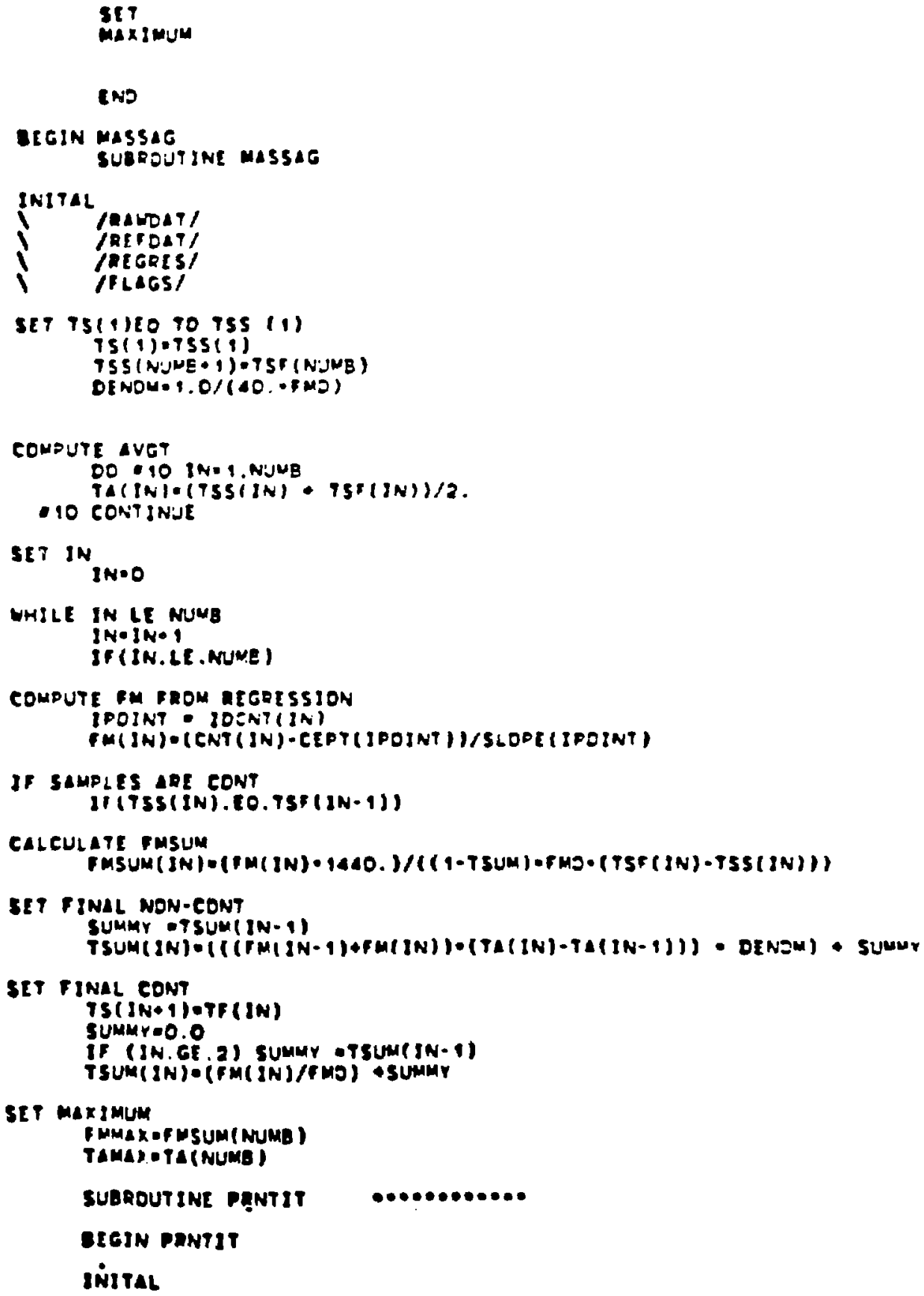


CMANEE TIME IN GINUTES TO ME MIN

TitLE anO hELOING

pintout data

ing

\section{DEGIN Tant It \\ SUERDUTANE PRNTIT}

INI TSL

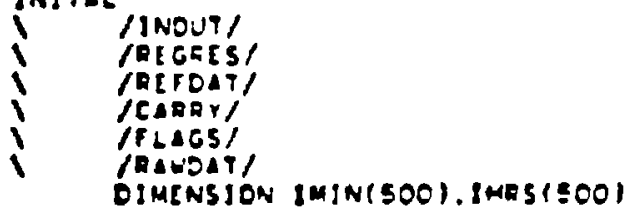

CHANEE TIME IN MINUTES TO HR.MIN DO $101 \cdot 1$. NUME

DMRST TI I)

IMPSI I IODMRS

IMINIJ I.EO. - (DHRS - FLOATIIMASII)I)

-10 CONTI INUE

TITLE ANO MEAOINE

VEITE (IPNT. 15) ITITL

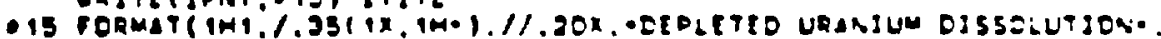

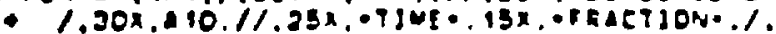

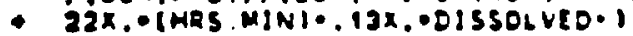

DRINTOUT DATA

Do 10 I- 1 , NUWB

WEITE (JPNT, OSI IMESII). JWINII) THSUM(I)

- I5 CoRmat(22x.14.14:.12.2.13x.111.01

- 10 cont inue

SUEROUTINE PLOTIT

DEGIN PLOTIT

IN่Tล

if rinst Tiate

c......

- sir uo

- axes

(.......

Dior poInts

if oont

E..... T

- if murtjolot

- c..... 


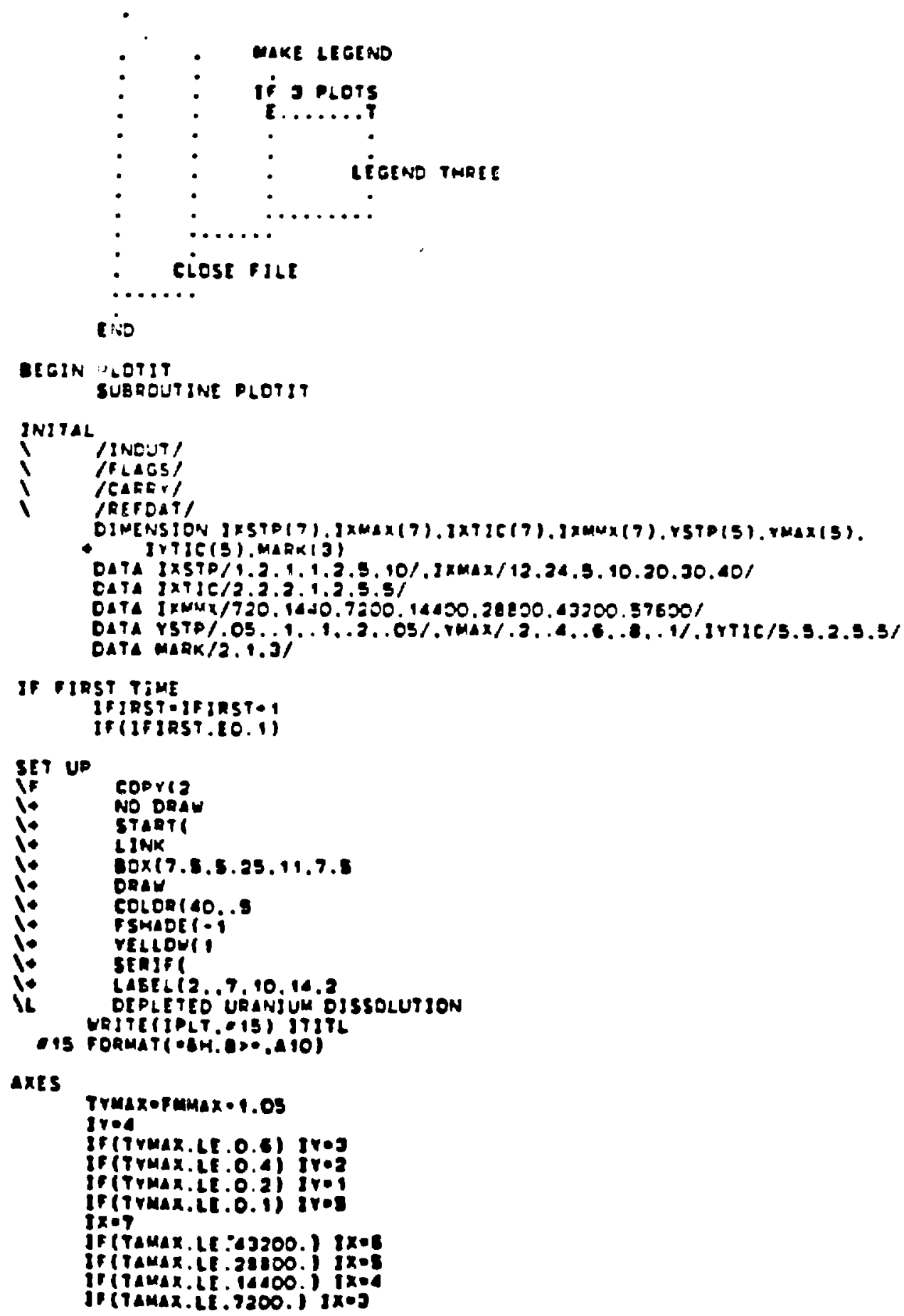




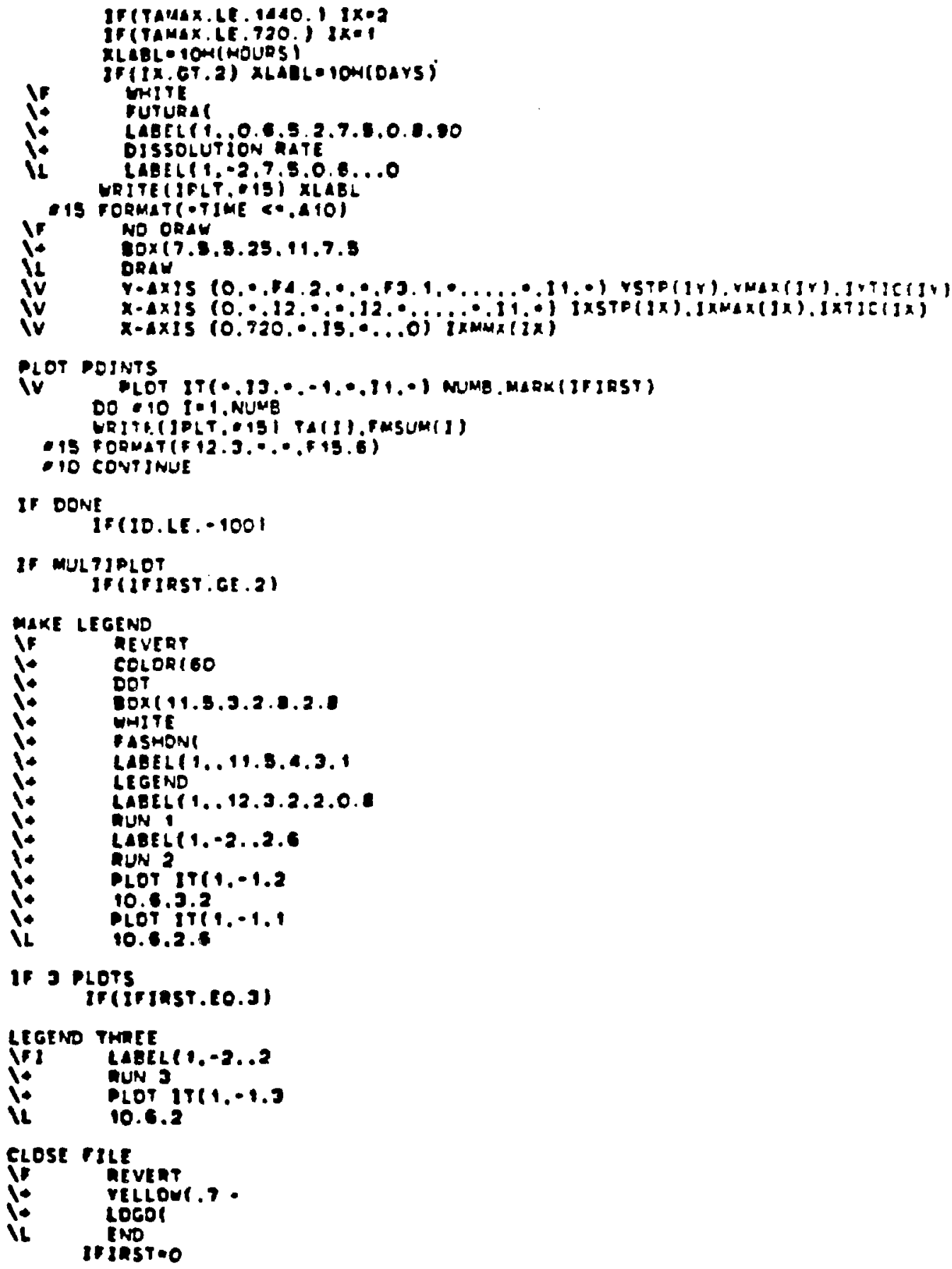




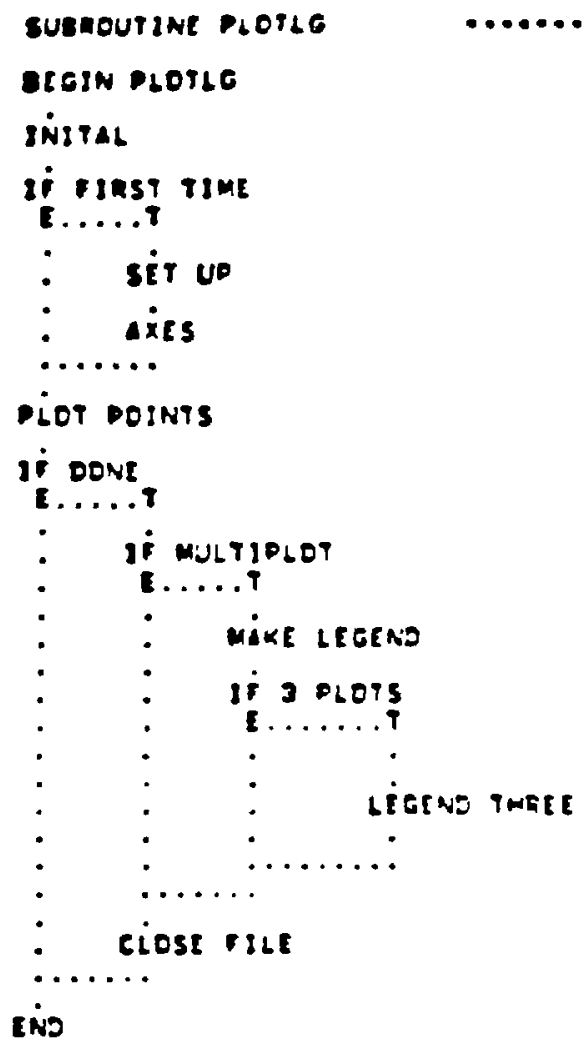




$$
\begin{aligned}
& \text { i. PLOT } 17 ! 1 . \cdot 1.1 \\
& \text { If } 9 \text { plots } \\
& \text { irifithst.co.3) } \\
& \text { LEGENO THAEE } \\
& \text { Ifl LABELI1.-2..2 } \\
& \text { 1. GUN } 3 \\
& 1+\text { CLOT } 1711, \cdot 1.3 \\
& \text { It } \quad 10.6 .2 \\
& \text { close ILE } \\
& \text { IfI REvet } \\
& \text { 1. VelLOH } 1.7 \\
& \text { it LOCOL } \\
& \text { IL IFIRSTOO }
\end{aligned}
$$


APPENDIX B

Listing of the Computer Program To Determine Dissolution Rates and Produce Plots of Mass Fraction Dissolved Versus Time 


\section{DEPOSTIOON AND RETENTION MODEIS}

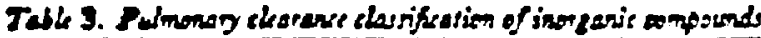

Class Y-Avid retesuon: cleased dowly (years)

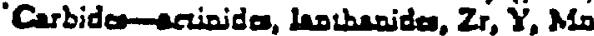

Sulfider-sode

Sulfates-pode

Curbosaterme

- Pbosphate-pode

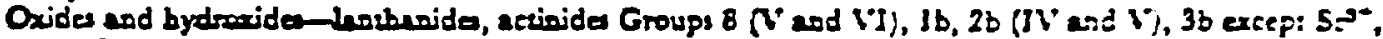
and $6 b$.

Malider-inorhanide Ausrides

Nitrawmode

Clas H-Mloderate reteation: interendiate dearance rate (weels)

Carbidea-Casions of all Clas W' bydroxides exeept bose linied a Cau Y carbides.

Sulfides-Groups 2a (V+VI), ia (IV-VI), Sa (IV-VI), Ib, 2b and 6b (V + VI).

Sulface-Groups 2a (IV-VII), and Sa (IV-VI)

Cusbonater-Lnthande, Bit and Group 2a (IV-VII)

Pbosphate- $\mathrm{Zn}^{2+}, \mathrm{Sn}^{2+}, \mathrm{MB}^{2+}, \mathrm{Fe}^{2+}, \mathrm{Bi}^{2+}$ and Locharides

Oxides and hydroxide Groups 2a (II-VII), 3a (III-VI), 4a (III-VI), 3a (II-VI), 6a (IV-VI), B, 2b (VI), 4b, 5b, and 7b Sct

Halides-lastharides (exeeps fuorides), Groups 2a, 3a (III-VI), 4a (IV-VI), 5a (IV-VI, 8, 1b, 2b, 3b $(I \mathrm{~V}-\mathrm{V}), 4 b, 5 b, 6 b$ and $7 b$

Nitrater-all cations whose bytiroxides sere Clacs $Y$ and $W$

Class D-Alinimal retention: rapid elearance (dayz)

Crebides-see trodroxides

Sulfider-all excep: Clus W

Sulfates-dl except Clas W

Carborster-all except Cus W

Phosphaterall except Clas W

Oxides and Hydroxide-Groupt Ia, 3 (II), in (II), 3a (II, III), 6s [III).

Halides-Groups la and 7.

Ditrate-all except Class $W$

Noble Gasen-Group 0

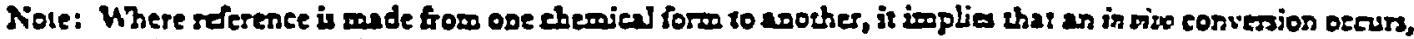
e.s. hydrolynis renction.

The following periodic table of the efernesis is used witb the foregoing clasuifeation.

\begin{tabular}{|c|c|c|c|c|c|c|c|c|c|c|c|c|c|c|c|c|c|c|}
\hline \multicolumn{19}{|c|}{ Group } \\
\hline Period & 20 & 2 & $3 b$ & $4 b$ & $3 b$ & $6 b$ & $7 b$ & \multicolumn{3}{|c|}{8} & $a b$ & $2 b$ & $3 a$ & $4 a$ & 52 & 62 & 78 & 0 \\
\hline 1 & $H$ & & & & & & & & & & & & & & & & & He \\
\hline II & i & Be & & & & & & & & & & & B & c & $\boldsymbol{N}$ & 0 & $F$ & Ne \\
\hline III & Ne & ME & & & & • & & & & & & & $\boldsymbol{N}$ & $S i$ & $\mathbf{P}$ & 5 & C & $A$ \\
\hline IV & $x$ & $\mathbf{c}$ & Se & $\mathbf{T} \mathbf{j}$ & $\mathbf{v}$ & $c$ & $\mathrm{Mn}$ & Fe & $c_{0}$ & $\mathrm{Ni}$ & $\mathrm{Cu}$ & $2 D$ & Ga & $\sigma_{e}$ & As & Se & Br & $x$ \\
\hline $\mathbf{V}$ & $R b$ & Sr & $\mathbf{Y}$ & $\mathbf{Z}_{\mathbf{T}}$ & $N B$ & Mo & TE & $R_{v}$ & $R h$ & $\mathrm{Pd}$ & As & Cd & In & $\mathrm{sn}$ & $\mathrm{Sb}$ & Te & 1 & Xe \\
\hline $\mathbf{v}$ & c. & Ba & L* & HI & $\mathrm{Ta}$ & $\mathbf{W}$ & Re & O. & It & $P_{2}$ & $A u$ & $H_{5}$ & $\pi$ & $\mathbf{P b}$ & $2 i$ & Po & At & $R_{n}$ \\
\hline VII & $F$ & n & Act & & & & & & & & & & & & & & & \\
\hline
\end{tabular}

\begin{tabular}{|c|c|c|c|c|c|c|c|c|c|c|c|c|c|c|}
\hline - Lenibrida . & $c$ & $\boldsymbol{r}$ & Nd & $P \infty$ & $8 m$ & Eu & Cd & $\mathbf{T b}$ & Dy & Ho & Er & $\operatorname{Tm}$ & $\mathbf{Y}_{\mathbf{b}}$ & $2 u$ \\
\hline 1 Astinide & $\mathbf{T b}$ & $\mathbf{P a}$ & $\mathbf{U}$ & $N p$ & $P u$ & Am & Cro & Bt & cr & $\mathbf{I n}$ & $F m$ & atd & No & $2 w$ \\
\hline
\end{tabular}

